
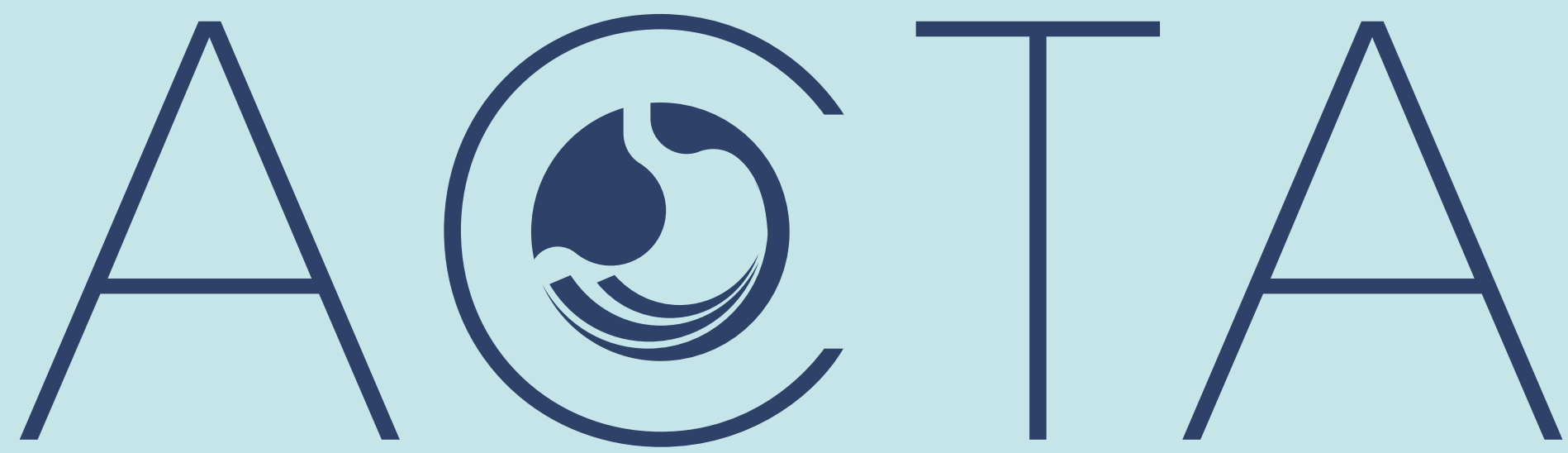

\title{
GASTROENTEROLÓGICA LATINOAMERICANA
}

Vol 50 Supl. N ${ }^{0} 1$ año 2020

ISSN: 2469-1119

SUPLEMENTO

\section{Recomendaciones para el diagnóstico y el tratamiento de tumores neuroendocrinos de origen gastroenteropancreáticos

\author{
Reunión intersociedades, \\ Academia Nacional de medicina
}

O'Connor J, Acosta Haab G, Armas I, Belli S, Bruno G, Cabanne A, Danilowicz K, Dioca M, Domenichini E, Falco A, Ismael J, Lastiri J, Losada Lopez F, Lupi S, Méndez G, Méndez P, Paganini L, Racioppi S, Ramisch D, Rampa R, Rizzolo M, Sánchez P, Traverso S, Tkatch J

Asociación Argentina de Oncología Clínica (AAOC), Sociedad Argentina de Cancerología (SAC), Instituto de Oncología A. Roffo, Sociedad Argentina de Endocrinología y Metabolismo (SAEM), Sociedad Argentina de Radiología (SAR), Colegio Argentino de Radiología Vascular e intervencionista (CARVI), Asociación Argentina de Biología y Medicina Nuclear (AABYMN), Asociación Argentina de Cirugía (AAC), la Sociedad Argentina de Patología (SAP), e Instituto Nacional del Cáncer (INC), Academia Nacional de Medicina. 


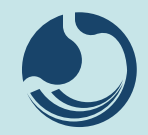

Órgano oficial
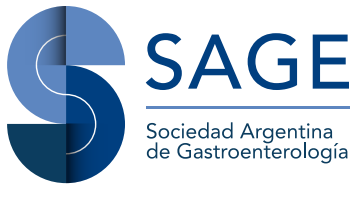

\section{EDITOR EN JEFE}

Jorge A. Olmos

Hospital de Clínicas General San Martín, Universidad de Buenos Aires, CABA.

\section{COMITÉ EDITORIAL}

Julieta Argüero

Hospital Italiano de Buenos Aires. CABA.

\section{María Marta Piskorz}

Hospital de Clínicas General San Martín, Universidad de Buenos Aires, CABA.

Juan Pablo Stefanolo

Hospital de Gastroenterología

Dr. Carlos Bonorino Udaondo, CABA.

\section{SECRETARIA}

Mariela García Muńoz

\section{PRODUCCIÓN Y EDICIÓN \\ Raúl Groizard}

\section{DISEÑO Y ARMADO DIGITAL}

Alejandro Javier Sfich

\section{CORRECTOR}

María Nochteff Avendaño

\section{PUBLICIDAD}

Establecer contacto con: Secretaría Revista Acta: actasage@gmail.com o Sociedad Argentina de Gastroenterología: sagesecretaria@gmail.com Tel.: 4816-9396/9391

\section{REVISORES NACIONALES}

Ana Adet
Fernando Barreyro
Sandra Basso
Claudia Bestani
Román Bigliardi
Maximiliano Bun
Fernando Cairo
María Cristina Cañero Velasco
Marcela Carballido
Sebastián Augusto Carrica
Mariano Cartier
Fernando Chirdo
Karina Collia
Luis Colombato
Rodolfo Corti
Alejandro Costaguta
Federico Cuenca Abente
Cecilia Curvale
Jorge Daruich
Juan Andrés De Paula
Martín De Santibáńez
Juan Manuel Díaz
Judith Doweck
Luis Durand
Nora Fernández
José L. Fernández
Luis Flores
Alfredo García
Aníbal Genna
Mariano Giménez

Ana Adet

Sandra Basso

Claudia Bestani

Fernando Cairo

María Cristina Cañero Velasco

Marcela Carballido

Mariano Cartier

Federico Cuenca Abente

Juan Andrés De Paula

Martín De Santibáñez

Luis Durand

Nora Fernández

Luis Flores

Aníbal Genn

Mariano Giménez
Andrea González
Nicolás González

Ramiro González Sueyro

Carlos González del Solar

Estanislao Gómez

Verónica Gorodner

Ubaldo Gualdrini

Martín Guidi

Silvia Gutiérrez

Hui Jer Hwang

Nadia Kujta

Juan Lasa

María Eugenia Linares

Carlos Miguel Lumi

Pablo Luna

Fernando Man

Mariano Marcolongo

Ricardo Mastai

Eduardo Mauriño

Ezequiel Matías Mauro

Alejandra Maynat

Roberto Mazure

Guillermo Mendez

Alberto Muñoz

Fabio Nachman

Alejandro Nieponice

Juan Manuel O'connor

Marina Orsi

Analía Verónica Pasqua

Silvia Pedreira

\section{Ramiro Perea}

María Marta Piskorz

Margarita Ramonet

Judith Cohen Sabban

Graciela Salis

Alicia Sambuelli

José María Sanguinetti

Fran Schlottmann

Edgardo Smecuol

Luis Soifer

Laura Sole

Silvia Susana Soler

Gabriel Solzi

Eduardo Sosa

Hugo Tanno

María del Carmen Toca

Lucio Uranga

Carlos Vaccaro

María Inés Vaccaro

Amanda Varela

Walter Vasen

Federico Villamil

Luis Viola

Mariano Volpacchio

Marta Wagener

Daniel Wainstein

David Zagalsky

Hugo Zandalazini

\section{REVISORES INTERNACIONALES}

Herbert Burgos

Henry Cohen

Angel Lanas

Xavier Llor

Natalie Nabon
Carolina Olano

Julio Carlos Pereira Lima

Mario Reis Alvares da Silva

José M. Remes-Troche

Roque Saenz
Asadur Jorge Tchekmedyian Marcelo Vela

Elena Verdú 

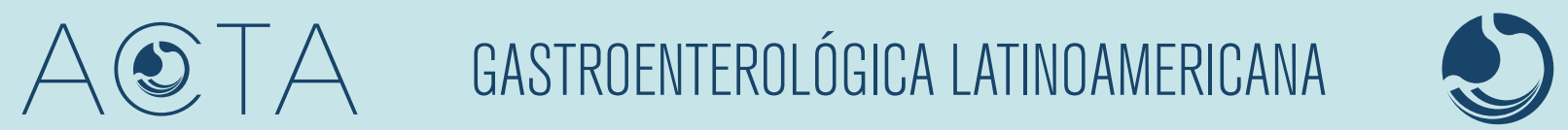

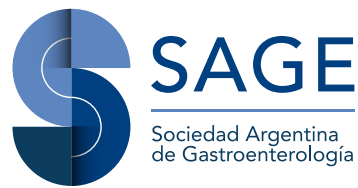

COMISIÓN DIRECTIVA SAGE - PERÍODO 2020

\section{PRESIDENTE}

Edgardo Smecuol

VICEPRESIDENTE

Fabio Nachman

\section{SECRETARIO}

Juan Manuel Romeo

\section{PROSECRETARIA}

María Dolores Matoso

\section{TESORERA}

Claudia Fuxman

PROTESORERA

Maricel Bellicoso

VOCALES TITULARES

Ramiro Calcagno

Federico Cassella

Juan Pablo Stefanolo

VOCALES SUPLENTES

María Eugenia Oregui

Josefina Etchevers

Claudia Bestani

\section{CONSULTOR EX-PRESIDENTE}

Jorge Olmos

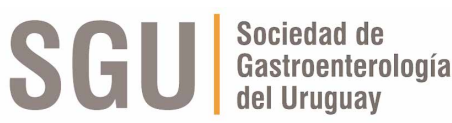

\section{COMISIÓN DIRECTIVA \\ SGU - PERÍODO 2019 - 2020 \\ PRESIDENTE}

Susana Kohen

1 er VICEPRESIDENTE

Adriana Raggio

$2^{\text {er VICEPRESIDENTE }}$

Andrés Taullard

SECRETARIA

Viviana Nachmann

TESORERO

Inés María Trucco

SECRETARIA DE ACTAS

Yéssica Pontet

ENCARGADO DE ASUNTOS INTERNACIONALES

Carolina Olano

ENCARGADO DE PROGRAMACIÓN NACIONAL

Virginia López

VOCALES

Claudia Méndez

Ximena Rodríguez

Suplentes preferenciales

María Di Pace

Juan José Arnejo

Pabla Ortega

COMISIÓN FISCAL

Miembros titulares

Cristina Dacoll

Beatriz Iade

Elena Trucco

Suplentes

Andrea Maucione

Patricia Gaggero

Ana Pose

Acta Gastroenterológica Latinoamericana es el órgano oficial de la Sociedad Argentina de Gastroenterología (SAGE) y la Sociedad de Gastroenterología del Uruguay (SGU). Propiedad intelectual № 231736. 


\section{Recomendaciones para el diagnóstico y el tratamiento de tumores neuroendocrinos de origen gastroenteropancreáticos}

\section{Reunión intersociedades, Academia Nacional de medicina}

O'Connor J, ${ }^{1}$ Acosta Haab G, ${ }^{2}$ Armas I, ${ }^{3}$ Belli S, ${ }^{1}$ Bruno G, ${ }^{4}$ Cabanne A, Danilowicz K, ${ }^{6}$ Dioca M,7 Domenichini E, ${ }^{1}$ Falco A, ${ }^{1}$ Ismael J, ${ }^{8}$ Lastiri J, ${ }^{3}$ Losada Lopez F, ${ }^{1}$ Lupi S, ${ }^{9}$ Méndez G, ${ }^{5}, 10$ Méndez P, ${ }^{11}$ Paganini L, ${ }^{1}$ Racioppi S, ${ }^{1}$ Ramisch D, ${ }^{10}$ Rampa R, ${ }^{12}$ Rizzolo M, Sánchez P,7 Traverso S, ${ }^{4}$ Tkatch J ${ }^{13}$

\footnotetext{
${ }^{1}$ Instituto Alexander Fleming.

${ }^{2}$ Hospital María Curie.

${ }^{3}$ Hospital Italiano de Buenos Aires.

${ }^{4}$ Fundación Centro Diagnóstico Nuclear.

${ }^{5}$ Hospital de Gastroenterología Dr. Carlos B. Udaondo.

${ }^{6}$ Hospital de Clinicas José de San Martín.

${ }^{7}$ Instituto A. Roffo.

${ }^{8}$ Instituto Nacional Cáncer Argentina.

${ }^{9}$ Hospital General de Agudos Jose María Ramos Mejía.

${ }^{10}$ Fundación Favaloro.

${ }^{11}$ Hospital Alemán.

12 Sociedad Argentina de Cancerología.

${ }^{13}$ Hospital General de Agudos Carlos G. Durand.

Ciudad Autónoma de Buenos Aires, Argentina.
}

Asociación Argentina de Oncología Clínica (AAOC), Sociedad Argentina de Cancerología (SAC), Instituto de Oncología A. Roffo, Sociedad Argentina de Endocrinologia y Metabolismo (SAEM), Sociedad Argentina de Radiología (SAR), Colegio Argentino de Radiología Vascular e intervencionista (CARVI), Asociación Argentina de Biología y Medicina Nuclear (AABYMN), Asociación Argentina de Cirugía (AAC), la Sociedad Argentina de Patología (SAP), e Instituto Nacional del Cáncer (INC), Academia Nacional de Medicina.

Acta Gastroenterol Latinoam 2020;50:1-33

\section{Puntos claves}

- Los tumores neuroendocrinos son poco frecuentes, aunque actualmente existe un incremento de su incidencia.

- El 50\% de los tumores neuroendocrinos se originan en el tracto gastrointestinal, donde existe mayor densidad de células neuroendocrinas.

- Se clasifican en secretores y no secretores, en función de la producción o no de hormonas.

- Los síntomas de presentación dependen de la localización, el tipo de tumor y el grado de diferenciación.

- La nueva clasificación de la patología permite establecer el pronóstico y determinar la estrategia de tratamiento.
- El diagnóstico se basa en la presentación clínica, la anatomía patológica, los marcadores séricos, las imágenes convencionales y los estudios funcionales.

- La cromogranina A es el marcador general más importante en los TNE funcionantes y no funcionantes.

- Los pacientes que se presentan con síndrome carcinoide tienen peor pronóstico y la complicación más grave es la cardiopatía carcinoide.

- La cirugía es el principal pilar del tratamiento para las formas localizadas.

- En las formas metastásicas, los nuevos tratamientos han demostrado disminuir la progresión del tumor y controlar los síntomas asociados a la secreción hormonal. 


\section{Índice}

\section{Introducción y metodología}

1.1 Epidemiología y datos locales.

2. Diagnóstico y clasificación

2.1 Anatomía patológica.

2.2 Estudios por imágenes: tomografía computada multidetector y resonancia magnética.

2.3 Estudios funcionales, medicina nuclear.

2.4 Marcadores tumorales.

3. Tratamiento

3.1 Cirugía. Consideraciones en tumores localizados y en enfermedad avanzada (metástasis hepáticas).

3.1.1 Tratamiento quirúrgico de los tumores neuroendocrinos. Enfermedad localizada.

3.1.2 Tratamiento quirúrgico de las metástasis hepáticas de tumores neuroendocrinos.

\subsection{Tratamiento regional hepático.}

3.3 Tratamiento sistémico.

3.3.1 Uso de análogos de somatostatina (SST) en TNE de origen gastrointestinal.

3.3.2 Tratamiento en TNE de origen pancreático.

3.3.3 Algoritmo final sobre tratamiento sistémico.

\section{Introducción}

Los tumores neuroedocrinos de origen gastroenteropancreático constituyen un grupo heterogéneo de neoplasias, que pueden originarse en diferentes órganos, aunque en su mayoría lo hacen en el tubo digestivo, ya que es donde existe mayor densidad de células neuroendocrinas. En más del $50 \%$ de los casos son de origen gastrointestinal. ${ }^{1}$

Los TNE se caracterizan por ser generalmente indolentes, aunque pueden tener un comportamiento biológico variable, según la localización del tumor primario, la morfología y los parámetros como el índice mitótico, o el índice de proliferación delular, Ki 67. Desde el punto de vista clínico, se dividen en secretorios y no secretorios, siendo estos últimos los más frecuentes. Existe un aumento en la incidencia de acuerdo con un último reporte de Dasari y colaboradores, que describen la presencia de síndrome secretorio en TNE-GEP en hasta en un $20 \%$ de los casos. ${ }^{2,} 3$ La heterogeneidad de esta patología y la complejidad para su manejo requieren un abordaje multidisciplinario, que permita optimizar recursos, evaluar nueva evidencia en el diagnóstico y el tratamiento de la enfermedad y mejorar la atención de los pacientes.

Por los motivos expuestos, el objetivo principal de este documento es generar guías o recomendaciones en nuestro país para el manejo de esta patología, tanto desde el punto de vista diagnóstico como terapéutico.

\section{Metodología}

Considerando la complejidad de esta patología, sumada al incremento en su incidencia, decidimos realizar recomendaciones sobre la base de datos actuales de la bibliografía y la experiencia local. Se propuso el tema: "tumores neuroendocrinos de origen gastroenteropancreáticos", debido a la complejidad que implica su manejo clínico. Se estipularon reuniones periódicas en la Academia Nacional de Medicina. El proceso se inició en septiembre de 2018, con la participación activa de representantes de diferentes sociedades médicas: la Asociación Argentina de Oncología Clínica (AAOC), la Sociedad Argentina de Cancerología (SAC), el Instituo A. Roffo, la Sociedad Argentina de Endocrinología y Metabolismo (SAEM), la Sociedad Argentina de Radiología (SAR), el Colegio Argentino de Radiología Vascular e Intervencionista (CARVI), la Asociación Argentina de Biología y Medicina Nuclear (AABYMN), la Asociación Argentina de Cirugía (AAC), la Sociedad Argentina de Patología 
(SAP) y el Instituto Nacional del Cáncer (INC). Asimismo, cada una de las sociedades recibió un mail con la invitación a participar en este proyecto. A su vez, cada una de las sociedades envió a uno o dos representantes, seleccionados de acuerdo con su experiencia e interés en la patología.

Se asignaron los diversos capítulos sobre diagnóstico y tratamiento, y se realizó una búsqueda no sistemática de la bibliografía, como así también una búsqueda de los datos de la experiencia local publicados o presentados en congresos locales o internacionales. Posteriormente se redactaron las recomendaciones de acuerdo con los temas asignados y con la participación activa de los representantes de las distintas sociedades. Se realizaron revisiones y sucesivas correcciones, de acuerdo con el criterio de los médicos intervinientes, hasta llegar al documento final, que cuenta con el aval de las sociedades participantes.

Presentamos aquí el artículo completo con las recomendaciones actuales de diagnóstico y tratamiento para los TNE-GEP. Este documento ha sido desarrollado en forma independiente, por iniciativa e interés de las sociedades médicas participantes, sin intervención ni soporte alguno de la industria farmacéutica.

\subsection{Epidemiología y datos locales}

En América Latina existen pocos datos sobre la epidemiología de esta patología, y en la Argentina, se han generado datos locales sobre la base de registros institucionales. Se pueden citar los datos del Grupo Interdisciplinario ARGENTUM, ${ }^{4}$ conformado por diferentes especialistas, que muestran las características principales en una población de 532 pacientes incluidos en el análisis, de los cuales 461 tienen diagnóstico de TNE-GEP. En esta serie de casos, el $26 \%$ presentó síndrome de hipersecreción, datos similares a los de una publicación reciente. ${ }^{3}$ Se observaron TNE-GEP bien diferenciados G1 en el 29,5\%, G2 en el 35,9\% y carcinomas neuroendocrinos G3 en el 9\%, de acuerdo con la clasificación de la Organización Mundial de la Salud (OMS) de 2010. Desde el punto de vista clínico, es relevante la división de estos tumores en bien diferenciados (G1, G2) y poco diferenciados (G3), por las implicancias desde el punto de vista diagnóstico y terapéutico. En el 59\% de los casos, los pacientes se presentaron con enfermedad avanzada al diagnóstico, si bien es posible que exista sesgo ya que la mayoría de los pacientes fueron evaluados por oncólogos.

Otra reciente publicación de Moncet y colaboradores $^{5}$ mostró la experiencia institucional en 105 pacientes a lo largo de 18 años de seguimiento. La mediana de edad al diagnóstico fue de 57,6 años (18-86). Al dividir el tiempo estudiado en tres períodos de seis años cada uno, se observa que en los dos primeros se mantuvo estable el número de tumores diagnosticados y, en cambio, en el último período hubo un incremento del $50 \%$.

Los TNE-GEP fueron los de presentación más frecuente, con 64 casos $(61 \%)$, con una mediana de edad de 63 años (20-86) y sin diferencia en cuanto a género. El sitio de tumor primario más común fue el intestino delgado, seguido de páncreas, apéndice, estómago y colorrectal. Al momento del diagnóstico, el 39\% tenía metástasis, lo que lo diferencia de la serie reportada por el grupo ARGENTUM en la que la proporción de TNE-GEP metastásicos fue del $78 \%(\mathrm{n}=11)$ en intestino delgado.

\section{Síndromes familiares}

Los TNE pancreáticos (p-TNE) corresponden al $30 \%$ de los TNE-GEP y pueden ser hereditarios o esporádicos. A pesar de que los tumores hereditarios representan el 20\% de los casos de TNE-GEP, ${ }^{6}$ es fundamental descartarlos para diagnosticar los tumores asociados e identificar a los familiares portadores aun cuando no existan antecedentes familiares. La neoplasia endócrina múltiple tipo 1 (NEM-1) es el síndrome hereditario más frecuente, aunque existen otros síndromes familiares como la enfermedad de Von-Hippel-Lindau (VHL), la esclerosis tuberosa (ET) y la neurofibromatosis tipo 1 (NF1 o enfermedad de Von Recklinghausen). Las mutaciones hereditarias en TNE-GEP se observan en genes supresores tumorales y la aparición de los tumores suele darse a una edad más temprana que en los casos esporádicos. ${ }^{7-10}$ Si bien el diagnóstico de certeza consiste en el estudio de la mutación, salvo el caso de NF-1, en la mayoría de los casos se puede realizar un diagnóstico de sospecha por el cuadro clínico que los síndromes presentan (Tabla 1). Los p-TNE en NEM-1 son los segundos tumores en frecuencia luego del hiperparatiroidismo primario ( $90-95 \%$ de frecuencia), por lo que es de buena práctica solicitar de manera rutinaria calcio sérico y parathormona (PTH), siendo que es más costo-efectivo en comparación con el estudio genético de la mutación de menina. Tanto en NEM-1 como en VHL los p-TNE suelen ser múltiples, por lo que el tratamiento quirúrgico en los TNE no funcionantes y en los gastrinomas estaría indicado en caso de tumores mayores a $2 \mathrm{~cm}$, lo que evitaría las cirugías radicales en pacientes jóvenes. ${ }^{11-13}$

En la Tabla 1 se muestran la frecuencia, el tipo y los criterios clínicos de cada uno de los p-TNE asociados. 
Tabla 1. Sindromes hereditarios en $p-T N E$.

\begin{tabular}{|c|c|c|c|}
\hline & $\begin{array}{l}\text { Frecuencia de } \\
\text { p-NEM }\end{array}$ & Tipo de p-TNE & Criterios clinicos \\
\hline $\begin{array}{l}\text { Neoplasia } \\
\text { Endocrina } \\
\text { Multiple Tipo } 1 \\
(\text { NEM-1) }\end{array}$ & $40-70 \%$ & $\begin{array}{l}\text { Gastrinoma (40\%), insulinoma }(10 \%) \text {, } \\
\text { glucagonoma/ vipoma }(<1 \%) \\
\text { no funcionante }(20-55 \%) \text {. } \\
\text { Suelen ser múltiples. }\end{array}$ & $\begin{array}{l}\text { Tumores en dos o más glándulas endocrinas: } \\
\text { - Hiperparatiroidismo primario (90-95\%). } \\
\text { - } \text { p-TNE }(40-70 \%) \text {. } \\
\text { - Adenomas hipofisarios (30-40\%). } \\
\text { - Otros: tumores adrenales, lipomas, TNE tímicos, } \\
\text { broncopulmonares y gástricos. }\end{array}$ \\
\hline $\begin{array}{l}\text { Von Hippel Lindau } \\
(\mathrm{VHL})^{14,15}\end{array}$ & $11-17 \%$ & $\begin{array}{l}\text { No funcionante }(98 \%) \text {. } \\
\text { Suelen ser múltiples. }\end{array}$ & $\begin{array}{l}\text { - } \text { Hemangioblastomas del SNC (60\%-80\%). } \\
\text { - } \text { Quistes pancreáticos ( } 30-70 \%) \text {. } \\
\text { - } \text { Angiomas retinianos (50-60\%). } \\
\text { - Feocromocitoma (20-25\%). } \\
\text { - } \text { p-TNE (11-17\%). } \\
\text { - Tumores endolinfáticos }(2-10 \%) \text {. } \\
\text { - Cistoadenoma epididimario. }\end{array}$ \\
\hline $\begin{array}{l}\text { Enfermedad } \\
\text { de Von } \\
\text { Recklinghausen } \\
\text { (NF-1) }\end{array}$ & $0-10 \%$ & $\begin{array}{l}\text { Somatostinoma duodenal } \\
\text { (mayor frecuencia), no funcionante, } \\
\text { gastrinoma, insulinoma } \\
\text { (menor frecuencia). }\end{array}$ & $\begin{array}{l}\text { Dos o más de los siguientes: } \\
\text { - }>6 \text { manchas "café con leche". } \\
\text { - }>2 \text { neurofibromas de cualquier tipo } 01 \text { plexiforme. } \\
\text { - Pecas en axilas o ingles. } \\
\text { - Gliomas del nervio óptico. } \\
\text { - }>2 \text { nódulos de Lisch (hamartoma de retina). } \\
\text { - Displasia de esfenoides o adelgazamiento de cortical } \\
\text { - } \text { de huesos largos. } \\
\text { Familiar de } 1^{\mathrm{er}} \text { grado afectado. }\end{array}$ \\
\hline $\begin{array}{l}\text { Esclerosis } \\
\text { Tuberosa }(E T)^{16,17}\end{array}$ & $\begin{array}{l}\text { Baja frecuencia } \\
\text { (sin datos) }\end{array}$ & Insulinoma & $\begin{array}{l}\text { - Lesiones cutáneas características ( } 100 \%) \text { : } \\
\text { máculas hipocrómicas o acrómicas, angiofibromas, } \\
\text { placas fibrosas cefálicas, fibromas ungueales. } \\
\text { - Convulsiones. } \\
\text { - Hamartomas en corazón, cerebro o riñones. }\end{array}$ \\
\hline
\end{tabular}




\section{Diagnóstico y clasificación de los TNE-GEP}

\subsection{Anatomía patológica}

Las neoplasias neuroendocrinas pueden desarrollarse en la mayoría de los órganos del cuerpo e incluyen distintas variantes. Históricamente se han clasificado de forma separada según el órgano de origen, y aunque compartían características en común tenían diferencias entre la terminología y los sistemas de clasificación, lo que generaba confusión en el diagnóstico.

En el 2018 la Organización Mundial de la Salud publicó una clasificación unificada para todas las neoplasias neuroendocrinas que comparten rasgos histológicos, inmunofenotípicos y ultraestructurales comunes. ${ }^{18}$

La clave de esta nueva clasificación es la distinción entre los TNE bien diferenciados y los carcinomas neuroendocrinos (CNE) pobremente diferenciados.
La subdivisión dual en TNE bien diferenciados y los CNE pobremente diferenciados se sustenta en sus diferentes grados de agresividad biológica, las respuestas al tratamiento, los factores de riesgo, la predisposición hereditaria y la relación con otras neoplasias. Su prevalencia relativa varía según el sitio de origen. ${ }^{18}$ Asimismo, evidencias genéticas en sitios anatómicos específicos respaldan esta subdivisión de TNE y CNE. ${ }^{19}, 20$

La clasificación de los TNE se basa en la gradación en tres categorías (G1 bajo grado, G2 grado intermedio, y G3 alto grado) según el conteo mitótico y el índice de proliferación con Ki-67. ${ }^{21,22} \mathrm{La}$ necrosis, si bien es reconocida como un factor adverso, no está en los parámetros de gradación. Los CNE no se gradúan porque son considerados de alto grado por definición; en cambio se tipifican como de células pequeñas o de células grandes (Tabla 2).

Tabla 2. Clasificación de los TNE.

Terminología

Conteo mitótico

(por $2 \mathrm{~mm}^{2}$ )
Índice de proliferación con $\mathrm{Ki}-67$ (\%)
Grado

$<3$

bajo

$3-20$

$>20$ intermedio

alto

\section{Carcinoma neuroendocrino pobremente diferenciado (CNE)}

CNE de células pequeñas de células grandes

WHO Classification Digestive System Tumours, 5ª edición 2019.

Los TNE G3 conservan el patrón histológico bien diferenciado (mínima a moderada atipia, patrón organoide, sin necrosis) con Ki-67 > 20\%. No se ha definido un límite superior para el conteo mitótico ni el índice de proliferación, pero los valores habitualmente son $\leq 20$ mitosis/10CGA/2 mm² y Ki-67 $\leq 55 \% .{ }^{22}$ Los TNE G3 pueden contener componentes de bajo grado o progresar a partir de TNE G1 o G2 tanto en el sitio primario como en metástasis en el transcurso de la enfermedad.

En cambio, la progresión de TNE G3 a CNE, si bien es infrecuente, no está totalmente descartada. ${ }^{23}$

Los CNE retienen $\mathrm{Ki}-67$ > 20\% como punto de corte, 
pero muestran una histología pobremente diferenciada, con células pequeñas o grandes. En páncreas a menudo presentan alteraciones en la expresión de $\mathrm{p} 53$, siendo negativos para retinoblastoma (rb) e INSM1 (Insulinomaassociated protein 1).

En muchos sitios anatómicos se encuentran neoplasias que exhiben elementos neuroendocrinos y noneuroendocrinos que morfológicamente pueden verse como poblaciones diferentes o íntimamente mezcladas. Los elementos neuroendocrinos en estas neoplasias "mixtas" o "combinadas" son comúnmente CNE; el componente no neuroendocrino puede ser glandular, escamoso o de otros linajes. Han sido denominadas neoplasias mixtas por el componente neuroendocrino y no neuroendocrino (MiNEN). Además, se ha descripto una diferenciación neuroendocrina en neoplasias no neuroendocrinas tratadas con quimioterapia, terapias dirigidas molecularmente o radioterapia.

\section{¿Qué información debe constar en el informe histopatológico?}

- La descripción del patrón morfológico (bien diferenciado versus pobremente diferenciado).

- En caso de contar solo con material citológico, este debe ser suficiente ( $\geq 500$ células) y apto para realizar técnicas de inmunohistoquímica.

- La confirmación diagnóstica obtenida mediante tinción con inmunohistoquímica para cromogranina, sinaptofisina, CD56 y/o factor de trascripción relacionado con insulina (INSM1).

- El grado histológico de acuerdo con los índices mitótico y de proliferación con Ki-67.

- El índice mitótico se expresa como número de mitosis en $2 \mathrm{~mm}^{2}$, evaluando por lo menos $10 \mathrm{~mm}^{2}$ en el área de mayor actividad mitótica. Las mitosis deben ser claras y deben descartarse los núcleos hipercromáticos, en cariorexis o apoptóticos. Debido a las variaciones de tamaño de los campos histológicos, debe determinarse el número de campos de gran aumento a 40x para $10 \mathrm{~mm}^{2}$ en cada microscopio según las tablas con ese propósito. ${ }^{24}$

- El índice de proliferación con Ki-67 debe ser informado como porcentaje de células positivas en el área de mayor densidad de núcleos marcados (hot spot). Todavía no ha sido estandarizado el método más preciso para su determinación. Se puede utilizar estimación ocular en la mayoría de los tumores neuroendocrinos, pero en los tumores con índices de Ki-67 próximos a los valores límites es recomendable el uso de conteo manual de 500 células, en imágenes fotográficas impresas o sobre la pantalla, de las áreas de mayor densidad, aclarando si hay menos células disponibles. El grado asignado según el índice de Ki-67 generalmente es mayor al conteo mitótico.

- La estadificación de los TNE, que debe seguir los criterios del capítulo específico de la $8^{\circ}$ edición de AJCC Staging System (2017). ${ }^{25}$ En cambio, CNE y las neoplasias mixtas se estadifican como carcinomas de los sitios respectivos.

- En resecciones quirúrgicas de TNE se recomiendan los protocolos del Colegio Americano de Patólogos (CAP), que incluyen descripción de los ganglios linfáticos (número de ganglios afectados/ganglios examinados), invasión vascular y perineural, profundidad de invasión, márgenes quirúrgicos, midiendo en $\mathrm{mm}$ si la distancia es menor a $5 \mathrm{~mm}$, multifocalidad, otras alteraciones, presencia de componente no neuroendocrino y/o de necrosis no isquémica (focal/puntual o difusa/ geográfica). ${ }^{24}$

Para los CNE pobremente diferenciados y mixtos se utilizan los protocolos de carcinomas de sitios respectivos.

En caso de recurrencia de la enfermedad se aconseja realizar una nueva biopsia, debido a probables discordancias histológicas entre el sitio primario y metástasis metacrónicas con potencial clínico significativo.

\subsection{Estudios por imágenes: tomografía computada multidetector y resonancia magnética}

Tanto los métodos convencionales como las imágenes funcionales son importantes para el diagnóstico y el manejo terapéutico de los pacientes con TNE-GEP. ${ }^{26} \mathrm{La}$ tomografía computada multidetector (TCMD) y la resonancia magnética $(\mathrm{RM})$ son las opciones convencionales apropiadas.

Siempre que sea posible, deben realizarse con contraste endovenoso (EV) dinámico (S 80-100\% y E 90-100\%), ya que los TNE son generalmente lesiones hipervascularizadas (realce arterial). Solo alrededor del 15\% pueden ser hipovascularizadas. ${ }^{27-29}$ En cuanto a las lesiones hepáticas, el patrón de realce y el porcentaje de lesiones con realce en fase arterial demostraron ser predictores independientes de secundarismo de origen neuroendocrino (versus adenocarcinoma)..$^{30}$ Además, el comportamiento de las lesiones con contraste EV dinámico permite sugerir el grado de diferenciación del TNE-GEP (G1 y G2 suelen ser hipervascularizados). ${ }^{31}$ 
La RM es de preferencia en aquellos pacientes candidatos a terapias ablativas o citorreductivas hepáticas, debido a su mayor sensibilidad y especificidad para detectar lesiones en el parénquima hepático. ${ }^{32,33}$

Otras modalidades imagenológicas que pueden ser de utilidad para la búsqueda y detección de tumor primario intestinal incluyen la enterotomografía (EnteroTC) o la enterorresonancia (EnteroRM) con contraste EV dinámico, con o sin técnica de enteroclisis. ${ }^{34,35}$

Dichas modalidades permiten duplicar la detección de lesiones enterales (con respecto a la TC convencional). Estos protocolos consisten en administrar contraste oral neutro (como metilcelulosa, manitol o polietilenglicol) para mejorar la distensión intestinal y favorecer la visualización de focos sospechosos de realce parietal posterior a la inyección de contraste EV. ${ }^{27-29}$

En la planificación prequirúrgica de los TNE de intestino delgado es de importancia definir el grado de compromiso nodal mesentérico, que suele evolucionar a reacción desmoplásica y mesenteritis retráctil. La fase arterial de la tomografía o la RM, particularmente en un plano coronal, brinda la posibilidad de evaluar el compromiso nodal mesentérico y su relación con la arteria mesentérica superior (AMS) y sus ramas. Ha sido propuesta una clasificación en cinco estadios de compromiso nodal con el objetivo de mejorar los resultados de la resección ganglionar, conservando la mayor longitud de intestino delgado posible $^{36}$ (Figura 1).

- Estadio ganglionar 0: no se observan ganglios linfáticos sospechosos de malignidad.

- Estadio ganglionar I: proximidad al intestino delgado sin compromiso de la AMS.

- Estadio ganglionar II: compromiso de ramas distales de la AMS, junto a su origen.

- Estadio ganglionar III: compromiso del tronco de la AMS. Se subdivide en bajo (III bajo) cuando existen cuatro o más ramas yeyunales proximales no comprometidas, y alto (III alto) cuando existen tres o menos ramas yeyunales proximales libres.

- Estadio ganglionar IV: compromiso del tronco de la AMS afectando a la primera rama yeyunal. Son considerados irresecables.

Figura 1. Estadificación clínica según compromiso ganglionar mesentérico. ${ }^{36}$

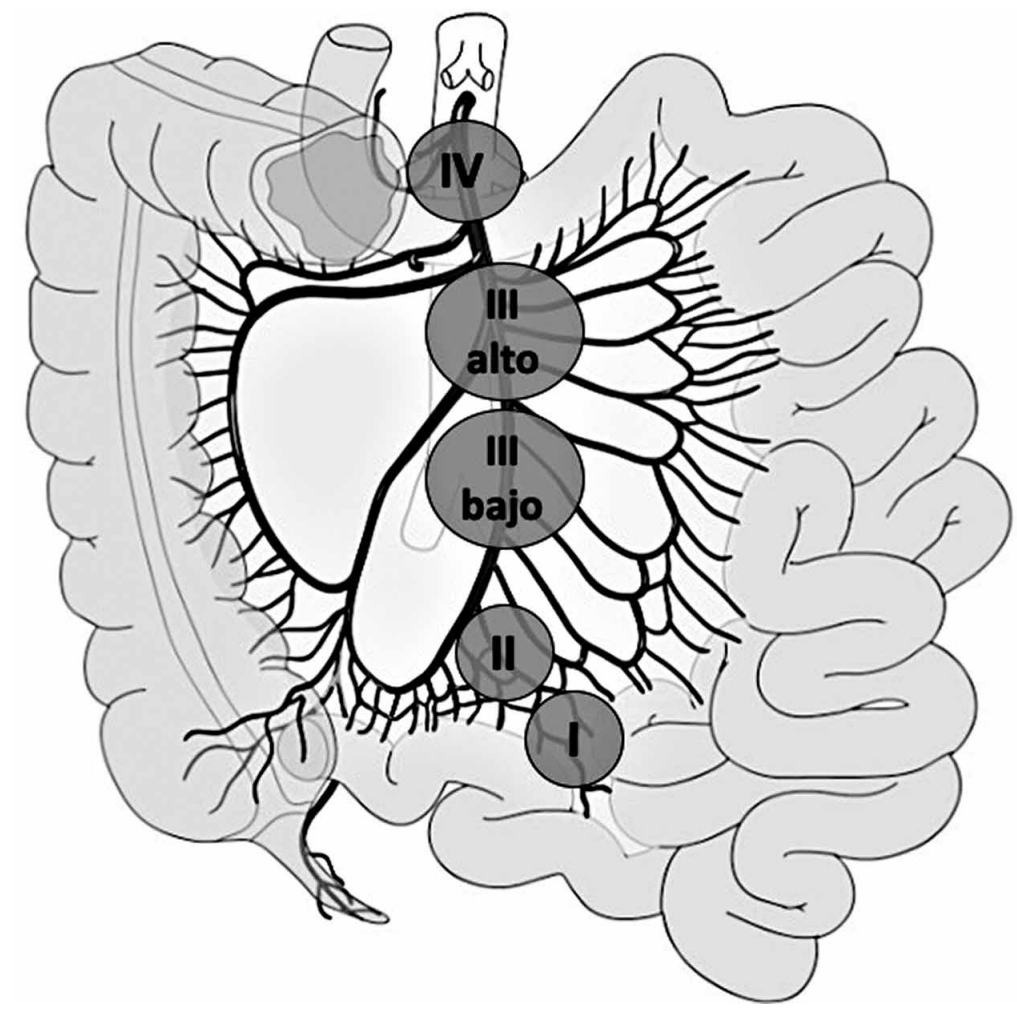




\section{TCMD y RM en el seguimiento}

La vigilancia continua de pacientes en tratamiento activo o expectante debe incluir imágenes convencionales (TCMD o RM) contrastadas, utilizando protocolos dinámicos multifásicos adecuados.

Aún no se ha definido la periodicidad óptima para realizar el seguimiento radiológico necesario en el monitoreo de la enfermedad.

En caso de indicación quirúrgica con intención curativa, debe considerarse la vigilancia periódica con imágenes convencionales y/o funcionales, según las técnicas que hayan resultado útiles al inicio. ${ }^{37}$

Se recomienda realizar imágenes cada 3-6 meses (TC o RM con contraste EV dinámico) en pacientes con TNE G1/G2 resecados (R0/R1) y cada 2-3 meses en pacientes con TNE G3. ${ }^{38,39}$

Sin embargo, ante pacientes con enfermedad metastásica, los intervalos de evaluación deben ser individualizados según factores relacionados al paciente, su enfermedad, las características del tumor, la terapéutica y los objetivos establecidos.

En pacientes jóvenes ( $<40$ años de edad) que solo presenten enfermedad hepática, se sugiere considerar la RM con contraste EV debido a su mayor sensibilidad y para minimizar la exposición acumulada de radiación.

\subsection{Estudios funcionales, medicina nuclear}

\section{1/123I MIBG}

El MIBG o metaiodobencilguanidina ingresa a las células neuroendocrinas por un mecanismo de captación activa a través del transportador de la epinefrina y se almacena en los gránulos neurosecretorios.

Se utiliza para realizar imágenes de tumores neuroendocrinos, particularmente los de origen neuroectodérmico (feocromocitomas, paragangliomas y neuroblastomas), si bien otros tumores neuroendocrinos también pueden visualizarse (por ejemplo: carcinoides, carcinoma medular de tiroides).

Si está disponible, el 123I MIBG se considera el radiofármaco de elección ya que presenta una dosimetría más favorable y proporciona imágenes de mayor calidad que el ${ }^{131}$ I MIBG, particularmente para la realización de imágenes SPECT/TC (Single Photon Emission Computed Tomography) que permiten una precisa localización anatómica.

La mayor vida media del ${ }^{131}$ I MIBG permite la adquisición de imágenes tardías, así como estimar la captación tumoral y medir la retención del radiofármaco en la lesión cuando se planea realizar terapia.
$\mathrm{Al}$ evaluar la captación tumoral y el tiempo de residencia, puede planearse el tratamiento con altas dosis de MIBG.

\section{Análogos de somatostatina, marcación con radio- trazadores}

Más del 85\% de los TNE gastrointestinales y pancreáticos tienen una alta afinidad por los receptores de somatostatina 2,3 y 5 .

Los análogos de somatostatina marcados con radioisótopos se utilizan para diagnóstico y terapéutica. En la actualidad, las metodologías de imágenes en medicina nuclear han avanzado con el desarrollo de las tecnologías híbridas, que permiten fusionar SPECT o PET con TC y/o RM.

Asimismo, el desarrollo de nuevos radiofármacos permite evaluar los distintos grados de diferenciación tumoral que se observan en los TNE, establecer pronóstico, evaluar recurrencia y realizar terapias dirigidas. ${ }^{40,41}$

${ }^{111}$ INDIO / 99 mTC

${ }^{111}$ In-DTPA-D-Phe-1-octreotide (análogo de somatostatina) se une principalmente a los receptores de somatostatina 2 y 5 (SSTR2 y SSTR5).

En su forma original, proporciona una imagen planar de cuerpo completo que requiere seguimiento durante al menos 24 horas luego de la inyección (dosis administrada $220 \mathrm{MBq}$ y dosis efectiva de $12 \mathrm{mSv}$ por procedimiento). Puede ser fusionada con tomografía computarizada de emisión de fotón único (SPECT) y TC, aprovechando la especificidad de octreótido y el detalle anatómico proporcionado por SPECT/TC, lo que mejora la precisión diagnóstica del método. ${ }^{42}$

\section{GALIO 68}

${ }^{68} \mathrm{Ga}$-DOTATOC, ${ }^{68} \mathrm{Ga}$-DOTANOC y ${ }^{68} \mathrm{Ga}-\mathrm{DO}-$ TATATE. Estas imágenes PET se fusionan con TC para mejorar la resolución anatómica del estudio.El estudio PET/TC con ${ }^{68}$ Galio-DOTA TATE-TOC o NOC se realiza a los 45-60 minutos posteriores a la inyección, con un barrido de cuerpo entero fusionado con una TC diagnóstica, a la que puede adicionarse contraste EV para una mejor caracterización de las lesiones.

Se administra una dosis máxima de $200 \mathrm{MBq}(5,4$ $\mathrm{mCi})$ por vía endovenosa, con una dosis efectiva de radiación de 4,8 mSv. ${ }^{43}$

La T muestra los diferentes sustratos y lugares de acción de los radioligandos (Tabla 3). 
Tabla 3. Radiotrazadores y avidez por SSRT.
111 In-Octreótido SPECT/TC
SSTR 2 y 5
99m Tc-Octreótido SPECT/TC
SSTR 2
${ }^{68 G a-D O T A T A T E ~ P E T / T C ~}$
SSTR 2
${ }^{68}$ Ga-DOTANOC PET/TC
SSTR 2-3-5
${ }^{68} \mathrm{Ga}-\mathrm{DOTATOC}$ PET/TC
SSTR 5

Aunque hay algunas diferencias en los perfiles de afinidad entre ${ }^{68} \mathrm{Ga}$-DOTATOC, ${ }^{68} \mathrm{Ga}$-DOTATATE y ${ }^{68} \mathrm{Ga}-$ DOTANOC, los estudios comparativos que utilizan la misma población de pacientes han mostrado solo pequeñas diferencias en la tasa de detección de lesiones. ${ }^{44,45}$

En la práctica clínica, el beneficio del uso de imágenes de PET con ${ }^{68} \mathrm{Ga}$-DOTA-péptido respecto de imágenes de SPECT con ${ }^{111}$ In-pentetreotide se debe principalmente a la detección de lesiones más pequeñas, detección de lesiones con baja a moderada expresión de SSTR y detección de lesiones adicionales que podrían modificar el manejo terapéutico de los pacientes. Además, el PET con ${ }^{68} \mathrm{Ga}$ DOTA-péptido es un método más rápido, con menor exposición de los pacientes a la radiación (la dosis efectiva para una administración típica de $100 \mathrm{MBq}$ de ${ }^{68} \mathrm{Ga}$ DOTATATE o ${ }^{68} \mathrm{Ga}$-DOTATOC es $2,1 \mathrm{mSv},{ }^{46}$ frente a 7,3 mSv por $100 \mathrm{MBq}$ de ${ }^{111}$ In-pentetreotide). También logra la detección de tumores primarios ocultos en hasta un 30-60\% en pacientes con estudios de imágenes convencionales negativos. ${ }^{46,47}$

\section{Metabolismo glucosídico}

18 Flúor-deoxi-glucosa (18FDG) es un sustrato que se incorpora al metabolismo de la glucosa en los diversos tejidos. La sensibilidad de 18F-FDG-PET en los TNE depende de su grado de diferenciación. Los tumores poco diferenciados (G3) presentan una escasa expresión de receptores de somatostatina y una elevada expresión de proteínas GLUT, que pueden ser detectados con 18F-FDG. ${ }^{44,48}$

No obstante, las últimas recomendaciones indican que en los TNE G3 se sugiere la combinación de ambos exámenes (PET/TC 18F-FDG y PET/TC ${ }^{68} \mathrm{Ga}-\mathrm{SA}$ ), con énfasis en los resultados de 18F-FDG en pacientes con valores Ki-67 más altos, lo que refleja un alto nivel de metabolismo glucolítico en pacientes de alto ries- go, con enfermedad agresiva y peor pronóstico, en los que la quimioterapia es favorable. Sin embargo, ${ }^{68} \mathrm{Ga}-$ DOTATATE también debe considerarse en este subgrupo, especialmente en el caso de una recaída durante un régimen de quimioterapia, ya que la positividad del receptor de somatostatina hace de la terapia metabólica dirigida con radiopéptidos (PRRT) una opción terapéutica potencial. El uso combinado de estos dos tipos de trazadores se conoce como PET/TC con trazador dual. Cuando se comparó la utilidad de los dos marcadores en los TNE de origen gastrointestinal y de diferentes grados, se encontró que en pacientes con tumores de bajo grado, ${ }^{68} \mathrm{Ga}$-DOTATATE era superior a $18 \mathrm{~F}-\mathrm{FDG}$. Sin embargo, en pacientes con TNE de alto grado, la evaluación del tumor era más completa cuando se integraron los dos ligandos. ${ }^{49,50}$

\section{Metabolismo de catecolaminas \\ ${ }^{18 F}$ DOPA}

${ }^{18} \mathrm{~F}$ fluro-dihidroxifenilalanina es un trazador del camino metabólico de las catecolaminas. Se caracteriza por tener una alta calidad de imagen, superior al octreoscan $y$ al PET/TC ${ }^{18} \mathrm{~F}-\mathrm{FDG}$, especialmente para los TNE de intestino medio. No proporciona información del receptor y se indica principalmente en los tumores con baja o variable expresión de receptores de somatostatina, como los tumores neuroectodérmicos. ${ }^{51}$

Es útil en pacientes con cáncer medular de tiroides, tumores neuroendocrinos de intestino medio (yeyuno, íleon), feocromocitomas, neuroblastoma o paragangliomas, y en pacientes con duda sobre la presencia de lesiones oncológicas metastásicas sincrónicas o metacrónicas, como por ejemplo en cáncer de mama. ${ }^{43}$

Presenta las desventajas de un alto costo y de una mayor dosis de radiación que el ${ }^{68} \mathrm{Ga}$ PET/TC (Figura 2). 
Figura 2. Algoritmo para el uso de radiotrazadores en TNE.

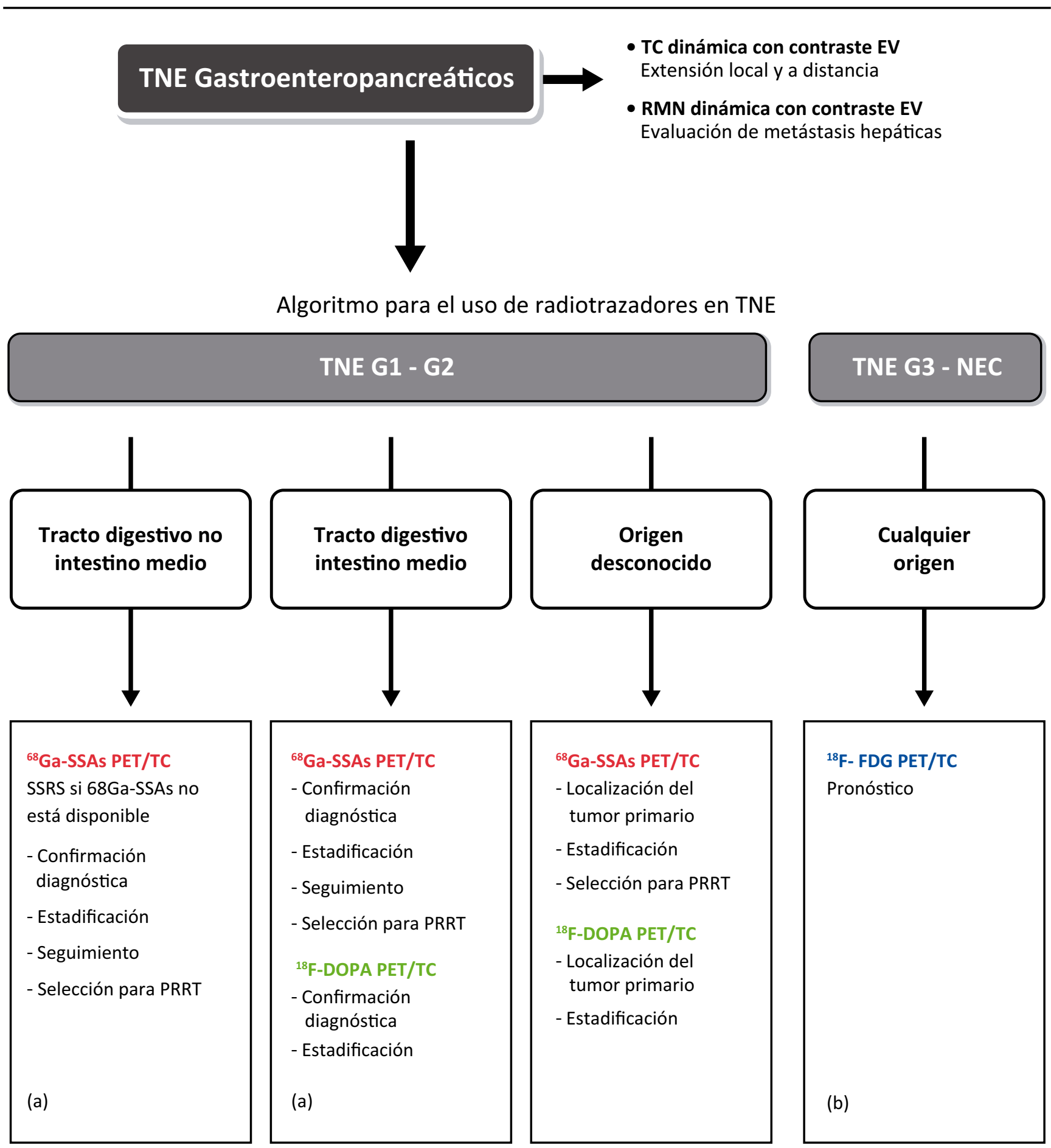

(a) La evidencia bibliográfica avala el uso de F18 FDG en aquellos pacientes con TNE bien diferenciados con un índice de proliferación superior al 10\% (Ki-67> 10\%).

(b) Los TNE bien diferenciados con índice de proliferación entre 20-55\% podrían beneficiarse con estudios específicos con análogos de somatostatina ( $\left.{ }^{68} \mathrm{Ga}-\mathrm{SSAs} \mathrm{PET} / \mathrm{TC}\right)$. 


\subsection{Marcadores tumorales}

El sistema endocrino difuso gastroenteropancreático sintetiza una gran variedad de péptidos bioactivos y hormonas en las células neuroendocrinas distribuidas en la mucosa gastrointestinal y en los islotes de las células de Langerhans del páncreas.

Los TNE-GEP pueden clasificarse en funcionantes (F/TNE-GEP) o no funcionantes (NF/TNE-GEP) según la capacidad de secretar hormonas específicas que produzcan un síndrome clínico asociado.

Un 25-30\% de los TNE-GEP son funcionantes. El diagnóstico de laboratorio de F/TNE-GEP requiere la demostración de una elevación de hormonas marcadoras específicas, junto con síntomas clínicos. El cuadro clínico dependerá de la hormona secretada por el tumor, así como de su localización y extensión (Tabla 4).

\section{Rol de los marcadores tumorales en el diagnóstico}

El TNE de intestino delgado deriva de las células enterocromafines productoras de serotonina; sin embargo, la mayoría de los TNE intestinales son clínicamente no secretantes. La tinción por inmunohistoquímica positiva en el tumor, junto con la detección de biomarcadores en suero o plasma, sin el correspondiente síndrome clínico, no permite la clasificación como un tumor funcionante. ${ }^{52}$ La determinación de la serotonina plasmática tiene, para la mayoría de los autores, poca sensibilidad y especificidad y, por ese motivo, no se recomienda su medición, ${ }^{53}$ pese a que existe algún dato diferente en la bibliografía. ${ }^{54}$ Para el seguimiento clínico de los TNE se mide un producto metabólico de la serotonina, el 5 hidroxiindolacético (5-HIAA), en una recolección de orina de 24 horas, porque guarda una buena correlación con la concentración plasmática de la serotonina. La determinación de 5-HIAA en orina de 24 horas debe realizarse en los pacientes con TNE del intestino delgado, así como en aquellos con síntomas sugestivos de síndrome carcinoide. Es indispensable, para evitar falsos positivos, cumplir con las siguientes restricciones dietéticas y farmacológicas, al menos durante los tres a cinco días previos a la recolección de orina: banana, palta, kiwi, ciruela, arveja, ananá, melón, tomate, espinaca, brócoli, coliflor, oliva, berenjena, frutas secas, quesos estacionados, bebidas alcohólicas, café y cigarrillo. Medicamentos como paracetamol, metisergi$\mathrm{da}$, naproxeno, jarabe para la tos que contenga ambroxol y fluorouracilo, y la levodopa, metildopa, fenotiazinas (clorpromazina, levomepromazina), heparina, isoniazi$\mathrm{da}$, antidepresivos tricíclicos, ACTH y aspirina pueden ser causa de falsos negativos. Tomando estos recaudos, la determinación del 5-HIAA tiene una sensibilidad del 70 al $75 \%$ y una especificidad cercana al $100 \%$ para la detección del tumor primario del yeyuno-íleon. ${ }^{55} \mathrm{La}$ aparición del síndrome carcinoide suele asociarse a la presencia de metástasis hepáticas y se produce un by pass en el clearance hepático de la serotonina. ${ }^{56}$ Suelen hallarse niveles muy elevados de 5-HIAA en orina de 24 horas $(\geq 300 \mu \mathrm{mol} \mathrm{o}$ $57 \mathrm{mg} / 24$ horas) en la enfermedad cardíaca carcinoide. ${ }^{52}$ El 5-HIAA debe medirse en condiciones basales y luego del tratamiento, para monitorear la respuesta terapéutica y detectar la progresión y la recidiva. Puede medirse junto con la cromogranina A para aumentar la sensibilidad de la prueba. No debe utilizarse como screening en el estudio de un paciente con diarrea sin diagnóstico de TNE. ${ }^{57}$

Como se mencionó previamente, los TNE pancreáticos corresponden al 30\% de los TNE-GEP, y de estos, un 40-55\% son funcionantes. El insulinoma debe sospecharse en los pacientes que presenten la tríada de Whipple: signos o síntomas de hipoglucemia, glucosa plasmática baja con resolución de los signos y síntomas luego de la normalización de la glucemia. Se debe solicitar la evaluación hormonal durante un episodio de hipoglucemia.

Los criterios diagnósticos que deben utilizarse son los siguientes: ${ }^{58,59}$

- Signos y/o síntomas de hipoglucemia.

- Glucemia $<55$ mg/dl.

- Insulina $\geq 3 \mathrm{U} / \mathrm{ml}$.

- Péptido $\mathrm{C} \geq 0,6 \mathrm{ng} / \mathrm{ml}$.

- Proinsulina $\geq 5 \mathrm{pmol} / \mathrm{l}$.

Una concentración de hidroxibutirato $\leq 2,7 \mathrm{mmol} / \mathrm{l}$ y un aumento de $25 \mathrm{mg} / \mathrm{dl}$ en la glucemia luego de 1 mg de glucagón EV indican hipoglucemia mediada por insulina.

En la misma muestra, deben solicitarse anticuerpos antiinsulina (hipoglucemia autoinmune) y medición de sulfonilureas (hipoglucemia inducida por fármacos).

Si la hipoglucemia no puede documentarse en la evaluación basal, debe inducirse a través de un test de ayuno de 72 horas, el cual se prolongará hasta la aparición de la tríada de Whipple o una glucemia $\leq 55 \mathrm{mg} / \mathrm{dl}$. Dos tercios de los pacientes serán diagnosticados dentro de las primeras 24 horas, y el total a las 72 horas.

La gastrina plasmática basal está elevada en el $99 \%$ de los pacientes con síndrome de Zollinger-Ellison (SZE), con una gastrinemia basal que habitualmente está diez veces por encima del valor máximo normal en casi un $40 \%$ de los pacientes. Utilizamos un valor de corte basal de $150 \mathrm{pg} / \mathrm{ml}$ como sospechoso de gastrinoma. En nuestro 
medio, no hay disponibilidad de secretina para realizar la prueba de estimulación en pacientes con aumentos marginales. Un valor de gastrina sérica 10 veces por encima del rango de la normalidad $(1000 \mathrm{pg} / \mathrm{ml})$, en presencia de un $\mathrm{PH}$ gástrico menor de 2, es diagnóstico de SZE. ${ }^{52,55}$

Se observan falsos positivos en la determinación de la gastrina, sobre todo en pacientes con disminución de la secreción de ácido clorhídrico, ya sea por la ingesta de inhibidores de la bomba de protones o por una atrofia gástrica autoinmune, gastritis asociada a Helicobacter pylori e insuficiencia renal, entre otros. El interrogatorio minucioso y la medición de anticuerpos anticélulas parietales, especialmente en pacientes con otras inmunopatías asociadas, evitan un diagnóstico errado de TNE.

Cuando se sospecha clínicamente un glucagonoma, la determinación de la glucemia, generalmente elevada, asociada a la del glucagón inapropiadamente alta (> 500$1000 \mathrm{pg} / \mathrm{ml}$ ), confirman el diagnóstico (valor normal de glucagón: menor a $50 \mathrm{pg} / \mathrm{ml}$ ). El glucagón puede estar marginalmente elevado en pacientes con ayuno, hipoglucemia, trauma, cirrosis, pancreatitis, diabetes, sepsis e insuficiencia renal. No obstante, algunos glucagonomas cursan con glucagón normal. ${ }^{60}$

En la Tabla 4 se resumen otros marcadores de tumores funcionales pancreáticos menos frecuentes, muchos de los cuales no pueden medirse en nuestro país. Además, dentro de los TNE pancreáticos funcionantes, se incluyen CRHoma con producción excesiva de hormona liberadora de corticotrofina $(\mathrm{CRH})$, calcitoninoma con producción de calcitonina, GHoma con secreción de somatotrofina, ACTHoma con producción excesiva de adrenocorticotrofina, ACTH y GRHoma con secreción de hormona liberadora de hormona del crecimiento, GHRH.

De los marcadores circulantes inespecíficos, la cromogranina A ( $\mathrm{CgA})$ es considerada el marcador genérico más sensible para todos los TNE, independientemente de su origen. Es una glicoproteína que suele estar presente en todas las células endocrinas y neuroendocrinas, en los gránulos de secreción de las hormonas peptídicas y de las catecolaminas. Los tumores derivados de estos tipos celulares secretan elevadas concentraciones de $\mathrm{CgA}$, lo que la convierte en un marcador tumoral.

Es una determinación sencilla y económica de realizar. Existen diferentes metodologías diagnósticas con valores de corte y unidades diferentes, por lo que es conveniente, durante el seguimiento longitudinal en un paciente, realizar la determinación siempre en el mismo laboratorio. La sensibilidad y la especificidad de todos los métodos pareciera ser semejante. ${ }^{61}$ Es útil como bio- marcador en todos los tumores neuroendocrinos bien diferenciados, independientemente de su localización, tanto en los tumores funcionantes como en los no funcionantes, en los que es muy importante porque es el único producto de secreción. No debe ser utilizada con el fin de diagnosticar un TNE pero es un buen marcador para evaluar la respuesta terapéutica e identificar la recidiva, especialmente después de una resección exitosa, aun cuando no haya evidencia radiológica de enfermedad. ${ }^{62}$

También señala el crecimiento de la masa tumoral y, por lo tanto, el pronóstico. Durante el seguimiento de un paciente con NEN, debe solicitarse la CgA asociada al control por imágenes.

En la Argentina la determinación de $\mathrm{CgA}$ es accesible y hay una larga experiencia en su utilización, con una sensibilidad del $83 \%$ y una especificidad del $96 \% .{ }^{63}$

$\mathrm{Al}$ analizar una determinación de $\mathrm{CgA}$ elevada deben descartarse otras situaciones clínicas no tumorales, como el uso de inhibidores de la bomba de protones, gastritis atrófica autoinmune, insuficiencia renal crónica (filtrado glomerular $<30 \mathrm{ml} / \mathrm{min}$ ), cirrosis hepática, insuficiencia cardíaca congestiva, enfermedades inflamatorias crónicas (lupus, artritis reumatoidea, enfermedad de Crohn), así como otras neoplasias secretantes de $\mathrm{CgA}$, como el carcinoma hepatocelular y el carcinoma medular de tiroides, entre otros cuadros clínicos.

La CgA no solo es un marcador en los TNE G1-G2, sino que puede estar elevada hasta en dos tercios de los pacientes con carcinomas neuroendocrinos (CNE) avanzados, ${ }^{64}$ pese a que los niveles suelen ser menores que en los pacientes con tumores bien diferenciados con igual extensión de la enfermedad. ${ }^{65,66}$ Por el contrario, la enolasa neuronal específica (NSE, por sus siglas en inglés) está más elevada en los tumores poco diferenciados que en los diferenciados, y su concentración se asocia significativamente con el volumen de enfermedad, el número de metástasis y con la sobrevida. ${ }^{67}$ Pero como la determinación de la NSE no está disponible en la mayoría de los centros asistenciales del mundo y tampoco en nuestro país, la $\mathrm{CgA}$ es el marcador tumoral circulante utilizado también en los CNE.

$\mathrm{La} \mathrm{CgA}$ es el marcador general mas importante en los TNE funcionantes y no funcionantes.

NETest, biopsia líquida. Biomarcadores circulantes

En la búsqueda de técnicas más precoces y precisas para detectar la enfermedad y evaluar la respuesta terapéutica, sin exponer al paciente con cáncer a la radiación frecuente con las imágenes convencionales, se han 
desarrollado nuevas técnicas no invasivas, utilizando herramientas moleculares en muestras de sangre periférica, a las que se denomina biopsias líquidas (biomarcadores circulantes), que facilitan y optimizan el manejo de los pacientes con cáncer.

Recientemente, se ha propuesto un análisis molecular del transcriptoma en la célula tumoral circulante (colección de todas las lecturas de genes presentes en una célula). La medición de estas muestras de ARN de la célula tumoral neuroendocrina se denomina NETest.

El NETest, a diferencia de la CgA u otro monoanalito como péptidos y hormonas, es una representación molecular multianalítica que provee una información biológica adecuada de la enfermedad neuroendocrina en curso.

El NETest, biopsia líquida, es útil para el diagnóstico de los TNE intestinales y pancreáticos. Un resultado plasmático positivo puede preceder en 1 a 2 años la identificación de metástasis en estudios por imágenes. Podria detectar la enfermedad residual posquirúrgica, el estadio de la enfermedad y la eficacia del tratamiento. Expone aspectos de la biología del tumor en tiempo real y sienta las bases para una estrategia terapéutica individualizada. ${ }^{68}$

Es necesario validar estos resultados que aparecen promisorios, porque hasta el momento solo el laboratorio Wren (Branford, Estados Unidos) realiza el NETest.

Tabla 4. Resumen de marcadores tumorales en TNE.

\begin{tabular}{|c|c|c|c|c|}
\hline Síndrome & Hormona/péptido & Localización & Cuadro clínico & Diagnóstico \\
\hline Carcinoide & Serotonina. & $\begin{array}{l}\text { Yeyuno- íleon, colon } \\
\text { proximal, apéndice. } \\
\text { Páncreas, pulmón, } \\
\text { recto. }\end{array}$ & $\begin{array}{l}\text { Flushing (rubicundez y transpiración), } \\
\text { diarreas, dolor abdominal intermitente. } \\
\text { Cardiopatía carcinoide (fibrosis de } \\
\text { válvulas tricúspide y pulmonar). }\end{array}$ & $\begin{array}{l}\text { 5-HIAA en orina de } 24 \text { horas. } \\
\text { CgA. }\end{array}$ \\
\hline Insulinoma & Insulina. & Páncreas. & Hipoglucemia. & $\begin{array}{l}\text { Prueba de ayuno } 72 \text { horas: Glu } \\
<55 \mathrm{mg} / \mathrm{dl} \text {. } P C \geq 0,6 \mathrm{ng} / \mathrm{ml} \text {. Ins } \\
\geq 3 \mathrm{U} / \mathrm{ml} \text {. Proinsulina } \geq 5 \mathrm{pmol} / \mathrm{l} \text {. }^{*}\end{array}$ \\
\hline $\begin{array}{l}\text { Gastrinoma } \\
\text { (Síndrome de } \\
\text { Zollinger- Ellison) }\end{array}$ & Gastrina. & Duodeno - Páncreas. & $\begin{array}{l}\text { Dolor abdominal, diarrea, reflujo } \\
\text { gastroesofágico, úlcera péptica. }\end{array}$ & $\begin{array}{l}\text { Gastrina en suero aumentada } \\
\text { (>1000 pg/ml); Prueba de } \\
\text { secretina. }^{*}\end{array}$ \\
\hline Glucagonoma & Glucagón. & Páncreas. & $\begin{array}{l}\text { Eritema necrolítico migratorio, pérdida } \\
\text { de peso, diabetes mellitus, glositis/ } \\
\text { queilitis/estomatitis. }\end{array}$ & Glucagón en suero aumentado. \\
\hline Somatostatinoma & Somatostatina. & $\begin{array}{l}\text { Páncreas, duodeno } \\
\text { yeyuno. }\end{array}$ & $\begin{array}{l}\text { Esteatorrea, colelitiasis y diabetes } \\
\text { mellitus. }\end{array}$ & $\begin{array}{l}\text { Somatostatina* en suero } \\
\text { aumentada. }\end{array}$ \\
\hline $\begin{array}{l}\text { Vipoma (síndrome } \\
\text { de Verner Morrison } 0 \\
\text { cólera pancreática) }\end{array}$ & $\begin{array}{l}\text { VIP (péptido intestinal } \\
\text { vasoactivo). }\end{array}$ & Páncreas. & $\begin{array}{l}\text { Diarrea acuosa, deshidratación, } \\
\text { hipopotasemia, hipoclorhidria. }\end{array}$ & VIP en suero aumentado. \\
\hline $\begin{array}{l}\text { TNE-GEP no } \\
\text { funcionante }\end{array}$ & No. & $\begin{array}{l}\text { Estómago, intestino, } \\
\text { páncreas. }\end{array}$ & $\begin{array}{l}\text { Síntomas por efecto de masa o } \\
\text { metástasis (sobre todo, hepáticas). }\end{array}$ & CgA, NSE, ${ }^{*} P .^{*}$ \\
\hline
\end{tabular}

Referencias: *No disponible en la Argentina.

5-HIAA: Ácido 5 Hidroxiindolacteico.

CgA: Cromogranina A.

Glu: Glucemia.

PC: Péptido C.

Ins: Insulina.

NSE: Enolasa neuronal específica.

PP: polipéptido pancreático. 


\section{Tratamiento}

\subsection{Cirugía. Consideraciones en tumores localizados y en enfermedad avanzada (metástasis hepáticas)}

\subsubsection{Tratamiento quirúrgico de los tumores neu- roendocrinos. Enfermedad localizada}

\section{Páncreas}

El tratamiento quirúrgico de los tumores neuroendocrinos pancreáticos representa una variedad disímil de propuestas terapéuticas, las cuales comprenden enucleación, duodenopancreatectomía (DPC), pancreatectomía distal con o sin esplenectomía, con especial hincapié en el vaciamiento ganglionar. La elección del tratamiento dependerá del tamaño, ubicación, relación con conducto principal, origen celular y características biológicas. ${ }^{69-71}$

\section{Tumores pancreáticos no funcionantes}

El control estricto sin indicar cirugía es controvertido, pero puede ser realizado en tumores pequeños no funcionantes de menos de $1 \mathrm{~cm}$, asintomáticos, con biopsia de bajo grado. Si el tamaño del tumor es de 1-2 $\mathrm{cm}$, existe un riesgo (muy bajo) de que haya metástasis ganglionares, por lo que se aconseja la enucleación en caso de ser superficial y sin contacto con ducto principal, con o sin linfadenectomía. ${ }^{72-74}$

Las Guías de la NCCN de 2018 sugieren la realización de resección anatómica con linfadenectomía regional para lesiones de más de $2 \mathrm{~cm}$ o en lesiones de menos de $2 \mathrm{~cm}$ con presencia de adenopatías positivas en imágenes. Las cirugías indicadas son duodenopancreatectomía con linfadenectomía para tumores ubicados en cabeza y pancreatectomía distal con esplenectomía y vaciamiento ganglionar para lesiones de cuerpo y cola. Solo se sugiere observación y seguimiento estricto a pacientes con lesiones menores de $2 \mathrm{~cm}$, con tumores bien diferenciados sin adenopatías positivas en pacientes con alto riesgo quirúrgico. ${ }^{75}$

Cada vez existe más evidencia que avala la linfadenectomía con preservación esplénica en resecciones distales, si no existe invasión de vasos esplénicos. ${ }^{76}$

\section{Tumores pancreáticos funcionantes}

\section{Gastrinomas}

En el caso de tumor oculto, se puede optar por estricto seguimiento del paciente o exploración quirúrgica con duodenotomía y ecografía intraoperatoria, lo que posibilita enucleación o resección local en caso de identificarlo. ${ }^{59,69}$

De presentarse como tumor exofítico o periférico, y alejado del conducto de Wirsung, existe la posibilidad de realizar una enucleación. Por el contrario, si el tumor es profundo, invasivo o se encuentra cercano al conducto de Wirsung, la indicación es la duodenopancreatectomía cefálica (DPC) en las lesiones ubicadas en la cabeza, y la pancreatectomía distal con o sin esplenectomía en los casos en los que se ubique en cuerpo y cola. ${ }^{72,75}$

\section{Insulinomas}

La mayor parte de estos tumores presentan comportamiento benigno, por lo tanto, en caso de ser un tumor exofítico o periférico, puede realizarse la enucleación por vía laparoscópica (especialmente para aquellos ubicados en cuerpo y cola del páncreas). Cuando la ubicación es profunda o contacta con el conducto de Wirsung, se indica la duodenopancreatectomía o la pancreatectomía distal, según corresponda. La vía laparoscópica es de elección en tumores distales con posibilidad de preservación esplénica. ${ }^{59,}$ 69, 75

\section{Glucagonomas}

Son, en su mayoría, tumores de comportamiento maligno, con invasión ganglionar y de ubicación preferente en cabeza. El tratamiento recomendado es la duodenopancreatectomía con linfadenectomía regional y la pancreatectomía distal con esplenectomía y resección de los ganglios peripancreáticos para los tumores localizados en cuerpo y cola del páncreas. En raras ocasiones, se recomienda la enucleación solo para aquellos tumores menores de $2 \mathrm{~cm}$, periféricos de cabeza o cola de páncreas, en pacientes seleccionados y acompañado de linfadenectomía. ${ }^{59,69,75}$

\section{Vipomas}

Se recomienda, según su localización, la duodenopancreatectomía cefálica o la pancreatectomía distal con resección de ganglios peripancreáticos y esplenectomía. Aunque los tumores menores a $2 \mathrm{~cm}$ y periféricos son raros, en caso de hallarlos, puede realizarse la enucleación con resección ganglionar. ${ }^{75}$

\section{Otros tumores funcionantes}

Las recomendaciones para el resto de los tumores neuroendocrinos (somatostatinoma, ACTH, péptido símil parathormona $[\mathrm{PTHrP}]$ y polipéptido pancreático $[\mathrm{PP}]$ ) es similar a la de los tumores no funcionantes. Aquellos menores de $2 \mathrm{~cm}$ y periféricos pueden ser enucleados, o puede realizarse una pancreatectomía distal con o sin esplenectomía y con o sin resección de ganglios peripancreáticos. Aquellos tumores que se encuentran más 
profundo, $>2 \mathrm{~cm}$ o invasivos, se tratan con DPC o pancreatectomía distal con resección ganglionar y del bazo, según corresponda. ${ }^{59,75}$

Hay que tener en cuenta que tanto en aquellos tumores $>2 \mathrm{~cm}$ o que presentan características de malignidad, debe hacerse la resección con márgenes negativos y linfadenectomía regional. ${ }^{72}$

Si bien, como se ha mencionado, la observación puede realizarse en lesiones pequeñas y no funcionantes, la resección quirúrgica ha demostrado mejor tasa de sobrevida. Resecciones menores, como enucleaciones, son técnicas menos complejas, con menor tiempo quirúrgico y menor pérdida de sangre, pero presentan mayor número de fístulas pancreáticas postoperatorias. ${ }^{77}$

En enfermedad avanzada, el primer lugar de metás- tasis es el hígado. En caso de que estas sean resecables, debe considerarse la resección tanto del primario como de las metástasis con intención curativa, ya sea resección simultánea o en 2 tiempos. Otro procedimiento quirúrgico a considerar es el debulking (citorreducción) en los pacientes con enfermedad avanzada, con el propósito de reducir la masa tumoral que podría provocar compresión por efecto de masa o, de ser funcionante, disminuir la secreción hormonal, sobre todo en aquellos con metástasis de insulinoma, asociadas o no a neoplasias endocrinas múltiples. ${ }^{69,75}$

Además, las resecciones del tumor primario, con el propósito de disminuir el "efecto de masa" y la secreción hormonal en enfermedad avanzada, han demostrado mejorar la sobrevida alejada de los pacientes ${ }^{78,79}$ (Figura 3).

Figura 3. Algoritmo en cirugía en TNE pancreáticos.

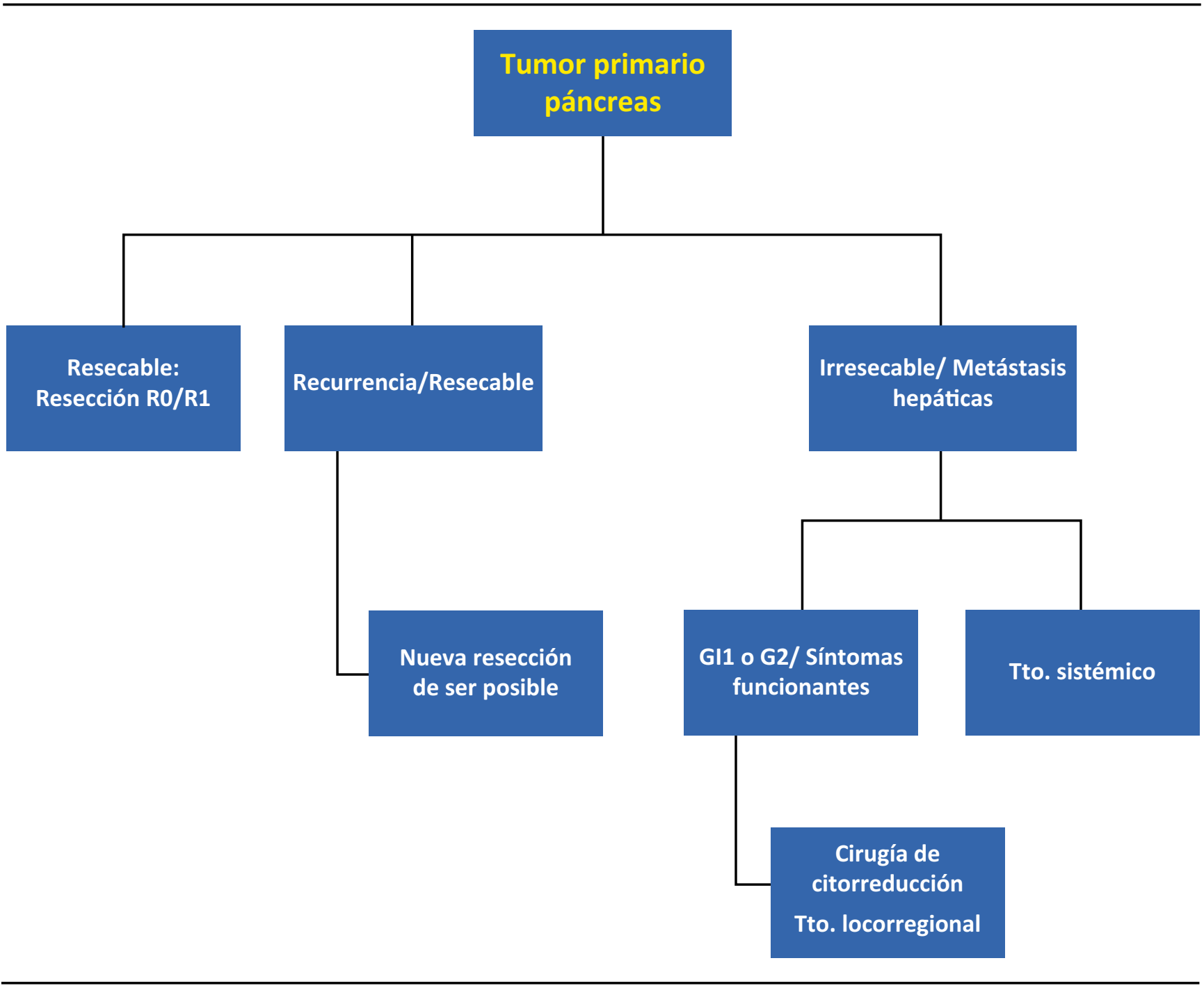




\section{Tumores gastrointestinales}

El tratamiento quirúrgico de tumores neuroendocrinos está indicado en caso de no ser candidatos a tratamientos endoscópicos en enfermedad localizada, y se realiza, generalmente, resección del órgano primario y linfadenectomía regional. En casos ocasiones de enfermedad a distancia, la resección del primario puede estar indicada.

\section{Estómago}

Los tumores neuroendocrinos gástricos son poco frecuentes, y su tratamiento difiere según el tipo de tumor, tamaño e invasión, con posibilidad de control endoscópico estricto sin resección, resección endoscópica, resecciones quirúrgicas atípicas y anatómicas con vaciamiento. ${ }^{80-82}$

Existen tres tipos de tumores neuroendocrinos: Tipo 1 (asociado a gastritis crónica), Tipo 2 (asociado a síndrome de Zollinger-Ellison) y Tipo 3 (esporádico, único, sin asociación). Se recomienda la resección endoscópica para los tumores prominentes Tipo 1. La antrectomía puede considerarse si el tumor aumenta significativamente de tamaño o aparecen nuevos tumores durante el seguimiento. Los casos Tipo 2 deberían resecarse y, de no hacerlo, llevar seguimiento estricto y resección endoscópica de tumores carcinoides prominentes.

Los tumores Tipo 3 son, usualmente, más agresivos, y debería realizarse la resección del primario con vaciamiento ganglionar. Para tumores tempranos y pequeños, puede considerarse la resección en cuña o endoscópica para los nódulos menores a $1 \mathrm{~cm}$, superficiales y/o de bajo grado. $^{75}$

\section{Duodeno, intestino delgado y colon}

Para las lesiones localizadas en duodeno, en primer término, debe intentarse la resección endoscópica ante tumores no invasores; la escisión local transduodenal y la duodenopancreatectomía cefálica serán indicadas ante la imposibilidad de tratamiento endoscópico. ${ }^{75}$

Para los pacientes que presentan tumor en el yeyuno, íleon o colon, se recomienda la resección quirúrgica junto con la linfadenectomía. La cirugía debería incluir un meticuloso examen de los vasos mesentéricos superiores, así como del intestino completo, ya que se han observado situaciones con lesiones sincrónicas en alto porcentaje. Las resecciones intestinales pueden hacerse por vía laparoscópica, siempre y cuando no se descuide la realización del correcto vaciamiento ganglionar mesentérico, que es el objetivo del tratamiento. .5, $74,75^{-1}$

La resección masiva de intestino puede generar intestino corto, con la consiguiente insuficiencia intestinal.
Anteriormente, esto era una cuestión "limitante" para la correcta resección del tumor primario, pero el mejor entendimiento de la insuficiencia intestinal y el tratamiento en unidades de rehabilitación y trasplante Intestinal permiten la resección oncológica necesaria. ${ }^{83,84}$

La resección del tumor primario además está indicada en presencia de enfermedad metastásica a distancia, cuando la resección metastásica también es curativa; en casos de tumores sintomáticos o complicados, y aunque es controvertido, la resección del tumor primario mejoraría la sobrevida aun si no se lograra una resección curativa. ${ }^{55}$

\section{Resecabilidad de las adenopatías en TNE del intes- tino delgado}

La evaluación para la resección de adenopatías mesentéricas relacionadas con los TNE de origen intestinal es preoperatoria y se basa en las imágenes, principalmente tomografía en fase arterial temprana y resonancia magnética. ${ }^{36}$

El radiólogo junto con el cirujano estudian las imágenes y las clasifican en 5 estadios de acuerdo con su proximidad con el tronco y las ramas de la arteria mesentérica superior AMS.

De manera simple se las agrupa en:

Fácilmente resecables: niveles 0,1 y 2 .

Difícilmente resecables: nivel 3:

- nivel 3 bajo: (más de 3/4 ramas yeyunales libres) resecables con dificultad y técnica con preservación de intestino.

- nivel 3 alto: (menos de 3/4 ramas yeyunales libres) generalmente irresecables.

Irresecables: nivel 4.

\section{Apéndice}

La mayor parte de los tumores neuroendocrinos del apéndice son pequeños, bien diferenciados y se detectan de forma incidental durante una apendicectomía. Para los tumores bien diferenciados menores de $2 \mathrm{~cm}$, el tratamiento es la apendicectomía.

Sin embargo, en caso de que el tumor sea de $1-2 \mathrm{~cm}$ con signos de mal pronóstico (invasión linfovascular o del mesoapéndice, o características histológicas atípicas), debería considerarse la realización de colectomía derecha, al igual que ante resección incompleta o tumores mayores 
de $2 \mathrm{~cm}$, dado el riesgo de metástasis ganglionares regionales a distancia. ${ }^{75}$

\section{Recto}

El tratamiento del tumor neuroendocrino de recto dependerá del tamaño y de la invasión mural. En lesiones menores a $1 \mathrm{~cm}$, incidentales, puede realizarse la resección por vía endoscópica. En lesiones mayores, la utilización de estudios por imágenes proporciona una estrategia adecuada para el posterior tratamiento. En tumores de
1-2 cm, se recomienda, de ser posible, la resección transanal o endoscópica, cuando no sean superiores a T2, es decir sin superar capa muscular, o no más de $2 \mathrm{~cm}$ de tamaño, aunque algunas series no demuestran mejor sobrevida en lesiones de 1-2 cm, independientemente de si corresponden a $\mathrm{T} 1$ o T2, con menores complicaciones con resecciones locales que con resecciones mayores. En caso de que el tamaño sea mayor a $2 \mathrm{~cm}$, la indicación es la realización de una resección anterior o abdominoperineal $^{75,85,86}$ (Figura 4).

Figura 4. Algoritmo en cirugía en TNE gastrointestinales.

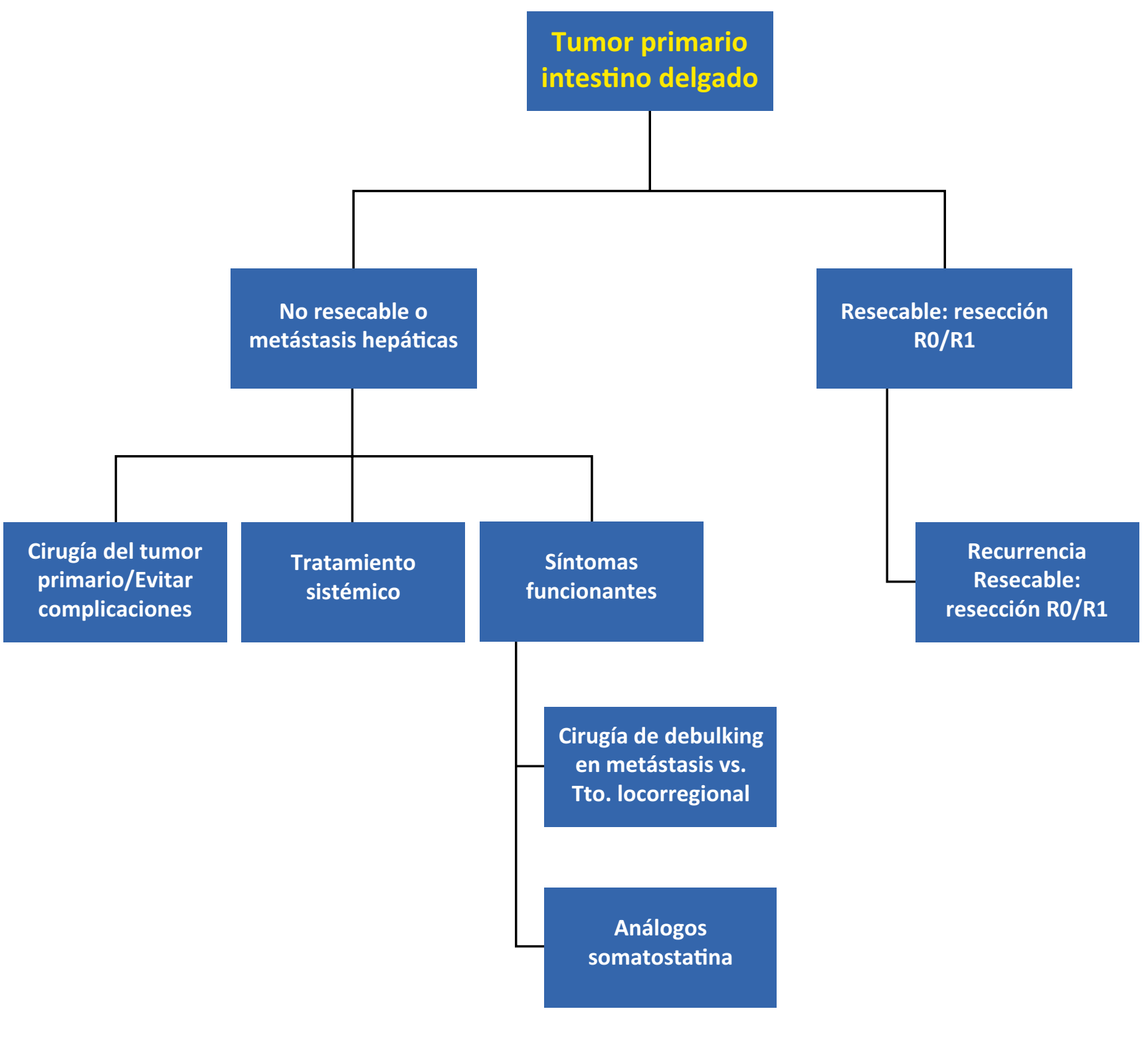


3.1.2 Tratamiento quirúrgico de las metástasis hepáticas de tumores neuroendocrinos

\section{Introducción}

La enfermedad metastásica en tumores neuroendocrinos es más prevalente en los de origen enteropancreático. Al inicio del diagnóstico, cerca de un 40-50\% de los pacientes presentan metástasis a distancia. Las metástasis son predominantes en hígado y en ganglios linfáticos y suelen ser más raras en hueso, pero probablemente estas últimas se encuentren subdiagnosticadas. ${ }^{87}$

Las metástasis hepáticas se presentan de forma sincrónica en el $60 \%$ de los pacientes y de forma metacrónica en el $40 \%$ restante. ${ }^{88}$

Existe consenso respecto de que la enfermedad de aparición simultánea tiene peor pronóstico e impacto en la sobrevida global y en la sobrevida libre de enfermedad, con mayor tasa de recurrencia en hígado.

Las opciones de tratamiento en metástasis hepáticas comprenden la cirugía resectiva, tratamientos locorregionales y trasplante hepático. Considerando la complejidad y la heterogeneidad de los TNE, se recomienda contar con adecuadas imágenes y correcta tipificación histopatológica para definir, en un marco de decisión multidisciplinaria, las posibilidades de tratamiento quirúrgico y locorregional en pacientes potencialmente resecables al inicio del tratamiento. ${ }^{87}$

\section{Cirugía}

Puede ser con intento curativo en enfermedad resecable (resección R0) o de citorreducción (70-90\% del volumen de enfermedad hepática).

La cirugía con intención de resección R0 puede comprender metastasectomías, segmentectomías múltiples o, incluso, resecciones mayores, con o sin el agregado de cirugía en dos tiempos, la cual ha demostrado claros beneficios en términos de sobrevida y de tasa de recurrencia. Hay series publicadas en las cuales la comparación entre el tratamiento de cirugía simultánea con el tumor primario y la cirugía diferida de las metástasis no ha demostrado diferencia en los resultados. ${ }^{88,89}$

La cirugía de debulking es considerada una alternativa terapéutica al tratamiento locorregional en pacientes con tumores funcionantes no controlados, especialmente en los que tienen síndromes funcionantes refractarios (insulinoma, glucagonoma, vipoma). ${ }^{90,} 91$ En pacientes con CNE o TNE de alto grado gastroenteropancreáticos, tanto la cirugía de debulking como las terapias locorregionales son desaconsejadas. ${ }^{92}$ No existen a la fecha estudios prospectivos aleatorizados que comparen los resultados obtenidos con cirugía de debulking respecto de las terapias locorregionales. ${ }^{93}$

La cirugía de debulking podría ser considerada en pacientes con tumores no funcionantes y síntomas relacionados con el tamaño tumoral hepático; sin embargo, el beneficio parece poco claro en pacientes asintomáticos. Incluso en caso de resección R0, existe una alta tasa de recurrencia a los 3 y 5 años. En pacientes con síndrome carcinoide, es importante el control de la hipersecreción de serotonina con análogos, previo a la cirugía, en virtud de prevenir la crisis carcinoide. ${ }^{87}$

\section{Trasplante hepático}

No es una opción recomendada en TNE de alto grado, aunque sí constituye una opción de tratamiento en pacientes altamente seleccionados con síndrome carcinoide u otros TNE funcionantes, extensa enfermedad hepática y en pacientes refractarios al tratamiento sistémico, incluidos análogos de somatostatina, interferón alfa, terapia locorregional y PRRT $^{89}$ (terapia con radiofármacos).

El trasplante hepático podría ser considerado en pacientes jóvenes (menos de 65 años), afectación de menos del $50 \%$ del hígado, resección del tumor primario al menos 1 año previo a la evaluación para trasplante, sin evidencia de enfermedad extrahepática, enfermedad estable al menos durante 1 año, TNE de origen gastrointestinal (drenaje sistema portal), y Ki-67 menor a $2 \% .{ }^{94-96}$ Las diferentes series muestran resultados de sobrevida a 5 años que van del $50 \%$ al $90 \%$, con una tasa de sobrevida libre de enfermedad del $20 \%$ al $70 \% .{ }^{96,97}$

\subsection{Tratamiento regional hepático}

\section{Introducción}

El desarrollo de metástasis hepáticas de los TNE es una presentación frecuente, con un impacto negativo en el pronóstico de enfermedad (sobrevida a 5 años variable entre $0-40 \%) .{ }^{98},{ }^{99}$ Entre el $46 \%$ y el $93 \%$ de los pacientes presentará enfermedad hepática al diagnóstico.

La cirugía es la única opción terapéutica que ofrece la posibilidad de curación en estos casos. Sin embargo, solo un $10-15 \%$ de los pacientes son candidatos a una resección curativa. ${ }^{100}$

Las terapias endovasculares dirigidas son aquellas que involucran la infusión de agentes terapéuticos intraarteriales de manera selectiva. Los quimioterápicos, materiales embolizantes y radioactivos son inyectados a través de los vasos nutricios tumorales con el objetivo de producir muerte celular. Son efectivos para el control de 
síntomas hormonales y para lograr respuestas locorregionales duraderas. ${ }^{98,101}$

\section{Indicaciones de terapia endovascular dirigida al hígado}

La presencia de metástasis hepáticas en el paciente con TNE se asocia a mal pronóstico, con una sobrevida a 5 años de 20-25\%. El abordaje multidisciplinario con un enfoque agresivo, que combina la cirugía y las terapias dirigidas, mejora la sobrevida y la calidad de vida de estos pacientes. ${ }^{98,100}$

La indicación de terapia endovascular hepática es para pacientes con enfermedad hepática dominante con síntomas relacionados a sobrecarga hormonal o al volumen tumoral; pacientes con rápida progresión de enfermedad hepática (especialmente, aquellos refractarios al tratamiento, irresecables o recurrentes) y como terapia adyuvante. A su vez, puede utilizarse como tratamiento puente a una cirugía resectiva o al trasplante hepático. ${ }^{101}$

En la actualidad, hay tres modalidades de tratamiento transarterial: la embolización arterial hepática o embolización blanda, la quimioembolización arterial y la radioembolización hepática con Ytrio (Y 90).

\section{Embolización y quimioembolización transarterial hepática}

Las metástasis hepáticas de TNE son generalmente hipervasculares y el 80-90\% de su irrigación depende de la arteria hepática. El hecho de que el $80 \%$ de la vascularización del parénquima hepático normal dependa de la vena porta explica el concepto de las terapias intraarteriales dirigidas. ${ }^{102}$

La embolización arterial hepática (EAH) o embolización blanda implica administrar un agente embolizante dentro de la rama nutricia arterial tumoral con el objetivo de inducir isquemia. La quimioembolización hepática transarterial $(\mathrm{QEH})$ agrega la entrega de un agente quimioterápico, sumando al efecto isquémico el componente citotóxico de la droga. Disminuir el flujo prolonga la retención de droga intratumoral hasta 20 veces más que en circulación sistémica. ${ }^{98,101}$

La técnica y la extensión del procedimiento depende del número, tamaño y distribución de las lesiones.

El lóbulo con mayor compromiso metastásico debe ser el primero en tratarse. En caso de compromiso hepático mayor al $75 \%$, la embolización debe realizarse en etapas que dependerán de la carga tumoral y de la tolerancia del paciente. ${ }^{103}$

Aunque no hay contraindicaciones absolutas, la trom- bosis portal, un pobre estado general y una reserva hepática insuficiente son contraindicaciones relativas. No se recomienda realizar el procedimiento en pacientes con niveles de bilirrubina entre $2-3 \mathrm{mg} / \mathrm{dl} .{ }^{104}$

El síndrome postembolización es la complicación más frecuente. Se caracteriza por dolor abdominal, náuseas, vómitos y fiebre. Se autolimita y solo requiere tratamiento sintomático. Algunos pacientes pueden presentar crisis carcinoideas y requerir octeótrido endovenoso para su tratamiento. Hay mayor predisposición a presentar abscesos postembolización en pacientes con derivaciones biliodigestivas, a pesar de recibir profilaxis antibiótica adecuada. Diferentes grupos recomiendan esquemas antibióticos en los días previos y preparación colónica para evitar esta complicación. ${ }^{105}$

La mayoría de los trabajos retrospectivos no aleatorizados han demostrado que tanto la EAH como la QEH reducen los niveles hormonales, palean síntomas y reducen el volumen tumoral en pacientes con metástasis hepáticas. ${ }^{99,101,106-108}$

Es preciso tener claro que no se ha demostrado un mayor beneficio terapéutico de la quimioembolización respecto de la embolización blanda. Los estudios publicados que comparan ambas técnicas entregan resultados heterogéneos y contradictorios, algunos muestran tasas superiores de sobrevida y/o seguridad para una técnica, y otros presentan resultados equivalentes. ${ }^{106}$ - 108

Actualmente, se encuentra en curso el estudio RETNET (Randomized Embolization Trial for NeuroEndocrine Tumor Metastases to the Liver), que recluta pacientes para compararlos en tres ramas, que incluyen la embolización blanda, la quimioembolización con lipiodol y la quimioembolización con esferas precargadas. El objetivo del trabajo es evaluar la sobrevida libre de progresión hepática, la toxicidad del tratamiento, el control de síntomas y la calidad de vida. ${ }^{107}$

\section{Radioembolización hepática con Y 90}

La radioembolización (RE) es la administración intraarterial selectiva de microesferas cargadas con Y 90, un emisor $\beta$ con una penetración tisular de $2,5 \mathrm{~mm}$.

Es un tratamiento ampliamente utilizado en pacientes con enfermedad primaria y secundaria hepática. Funciona como una braquiterapia intraarterial que deposita el isótopo radioactivo en la vasculatura tumoral y peritumoral sin oclusión del flujo. ${ }^{109}$

Se realiza en dos etapas: evaluación inicial y administración del reactivo. En la primera etapa, una angiografía diagnóstica evalúa la anatomía arterial hepática con una eventual embolización selectiva arterial, con el objetivo de 
evitar el suministro no dirigido de microesferas de Y 90 a órganos adyacentes. En el mismo proceso, se inyecta un macroagregado de albúmina marcada con $99 \mathrm{mTc}$ para determinar la presencia de shunt hepato-pulmonares. ${ }^{110}$ La RE representa una alternativa viable, especialmente para los pacientes en quienes las terapias tradicionales han fallado. Es un método seguro, efectivo y con una alta tasa de control de enfermedad y alivio de síntomas (91\% y $79 \%$, respectivamente). ${ }^{111}$

La NCCN (National Comprehensive Cancer Network) y la ENETS (European Neuroendocrine Tumor Society) recomiendan cualquiera de las tres técnicas y no se definen por un procedimiento específico, dada la ausencia de trabajos comparativos grandes y bien diseñados. ${ }^{87,112}$
Por otra parte la ENETS propone un algortimo práctico que adaptamos para su aplicación en la práctica asistencial (algoritmo en metástasis hepáticas de TNE) ${ }^{87}$ (Figura 5).

\section{Conclusión}

Existe un claro beneficio de las terapias intraarteriales locorregionales hepáticas para pacientes con enfermedad irresecable, en progresión, con síntomas hormonales o relacionados al volumen tumoral.

La técnica utilizada se definirá según las características individuales de los pacientes, el medio en que se desempeña el profesional y la experiencia del radiólogo intervencionista actuante.

Figura 5. Algoritmo en metástasis hepáticas.

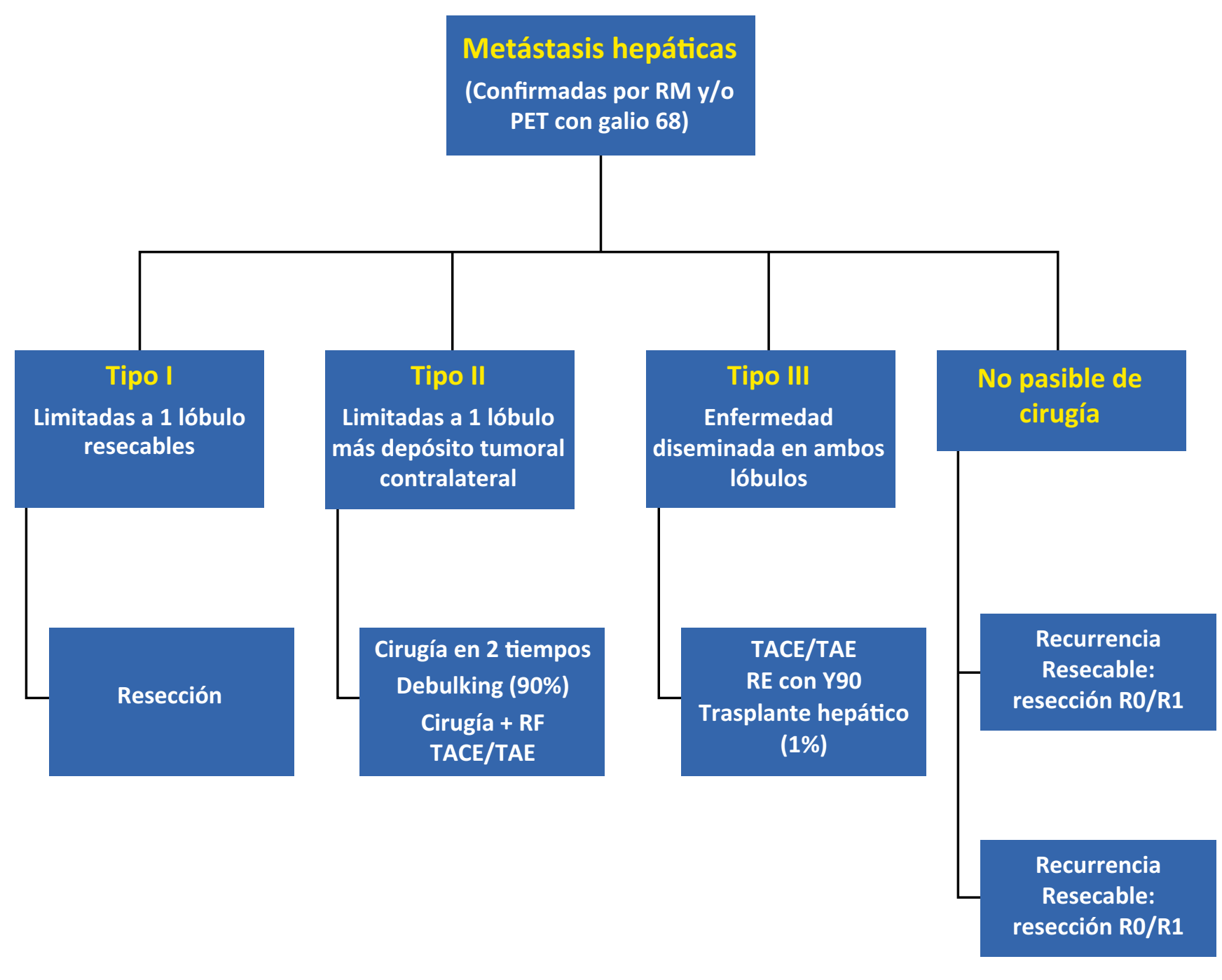




\subsection{Tratamiento sistémico}

\subsubsection{Uso de análogos de somatostatina (SST) en TNE de origen gastrointestinal}

Estos tumores bien diferenciados se caracterizan por tener expresión de receptores de somatostatina. El blanco específico de los análogos de SST son los receptores subtipo 2 y 5 , y aproximadamente un $80 \%$ de los TNEGEP expresa estos receptores. ${ }^{113}$ En la Argentina, el único estudio que evaluó la expresión de receptores de SST en pacientes con TNE-GEP fue publicado en $2009,{ }^{114}$ a través del Grupo ARGENTUM, en el cual se observaba la expresión de receptores subtipos 2 a y 5 en el $86 \%$ y el $62 \%$ de los casos, respectivamente, en TNE bien diferenciados en esta serie de 100 pacientes.

Desde el punto de vista clínico, es importante la diferenciación entre los tumores funcionantes (síndrome carcinoide) y los no funcionantes, ya que esta diferenciación tiene implicancias directas en la estrategia de tratamiento sistémico en este subgrupo de pacientes. En el síndrome carcinoide, la diarrea ocurre en aproximadamente un $80 \%$ de los pacientes y se asocia principalmente a la secreción de serotonina, mientras que el flushing característico se reporta entre un $60-80 \%$ de los casos.

Afecta principalmente el área malar y la región anterior del tórax, en general, de corta duración, y puede ser provocado por ciertos tipos de bebidas alcohólicas y alimentos ricos en tiraminas. Otros síntomas, por ejemplo, sibilancias por broncoconstricción, se presentan en alrededor del 10\% de los casos. La complicación más seria del síndrome es la cardiopatía carcinoide, que se presenta en aproximadamente un $40-60 \%$ de los pacientes con síndrome carcinoide.

En relación con los tumores funcionantes, es decir, aquellos con síndrome carcinoide, el tratamiento de primera línea es el uso de a SST, y existen dos compuestos comerciales, ocreótido y lanreótido, ambos con demostrada eficacia para el control de síntomas en esta patología.

El uso de ocreótido de larga acción fue aprobado para el tratamiento de diarrea severa y flushing asociado a tumores neuroendocrinos funcionantes, sobre la base del estudio de Rubin ${ }^{115}$ y colaboradores, en el cual se observó reducción de los síntomas en el 66,7\% y 71,4\% de los casos con dosis de 20 y $30 \mathrm{mg}$ cada 28 días, respectivamente. En una serie retrospectiva con 69 pacientes, ${ }^{116}$ en la cual se evaluó eficacia de lanreótido, se observó control de síntomas en el 74\% de los casos. Por su parte, y de forma más reciente, en el estudio ELECT, ${ }^{117}$ estudio aleatorizado, doble ciego, fase III, durante un período de 16 semanas, se incluyó a 115 pacientes y se utilizó lanreótido como tratamiento del síndrome carcinoide. Se observó reducción en la necesidad de rescate con ocreótido (punto final primario) en el 33,7\% del grupo de lanreótido versus el $48,5 \%$ en la rama placebo.

Dentro de las opciones posibles en síndrome refractario, existe otro agente, denominado telotristat etiprato, un agente oral inhibidor de la tirosina hidroxilasa. En el estudio TELESTAR, ${ }^{118}$ se comparó la aplicación de dos dosis diferentes de telotristat versus placebo en pacientes con diarrea bajo tratamiento con dosis estándar de octreótida. La respuesta al tratamiento en la rama experimental fue del $44 \%$ y del $42 \%$ dos veces por día $250 \mathrm{mg}$ o 500 $\mathrm{mg}$, respectivamente, comparado con el $20 \%$ de los que recibían placebo, con efecto durable en el tiempo. En este estudio se observaron beneficios en relación con la diarrea y reducción de 5-HIAA. El uso de esta droga no ha sido aprobado en la Argentina. Otra opción en el caso de falta de control de síntomas, con el tratamiento de a SST, es el uso de interferón alfa, ${ }^{119,120}$ con dosis de 3 a 5 millones de unidades 3 veces por semana. La evidencia en favor de su uso es limitada, aunque en la práctica puede tener un rol en el control de síntomas en combinación con a SST. Se debe tener en cuenta la toxicidad de este agente.

En cuanto a su efecto antiproliferativo, dos estudios pivotales han mostrado beneficios con el uso de los a SST: PROMID ${ }^{121}$ y CLARINET. ${ }^{122}$ El estudio PROMID, estudio aleatorizado que comparó el uso de ocreótido $30 \mathrm{mg}$ cada 28 días versus placebo en pacientes con TNE de origen gastrointestinal, con tumores bien diferenciados $\mathrm{G} 1$, funcionantes y no funcionantes, mostró ventajas en términos de tiempo a la progresión, a favor de la rama de tratamiento activo, 14,3 meses versus 6,0 meses (HR $=0,34$, IC 95\%, 020-0,59, $p=0,000072$ ). El estudio CLARINET fue un estudio aleatorizado, que comparó el uso de lanreótide 120 mg cada 28 días versus placebo en pacientes con TNE-GEP, es decir con la inclusión de TNE pancreáticos y de origen desconocido bien diferenciados G1 y G2 (pero con Ki 67 hasta 10\%). El estudio fue positivo en términos de sobrevida libre de progresión (SLP), mediana no alcanzada en la publicación inicial del estudio, versus 18 meses en la rama de placebo (HR = 0,35, IC 95\%, 0,16-0,80 en los de origen GI y HR = 0,58, IC 95\%, 0,32-1,04, en los de origen pancreático) (Tabla 5).

\section{Evidencia clínica con otros agentes en TNE de origen GI}

El estudio RADIANT IV ${ }^{123}$ evaluó los beneficios del uso de everolimus $10 \mathrm{mg} /$ día vo, de forma continua, comparado con placebo. El everolimus es un inhibidor 
Tabla 5. Estudios pivotales de análogos de somatostatina, efecto antiproliferativo.

Características

Ramas del estudio

Tumor primario

Grado de diferenciación

Tumor funcionante

Expr recept SST

Progresión previo al ingreso

al estudio

Punto final primario

\section{PROMID (85 pacientes)}

Octr LAR $30 \mathrm{mg}$ (42 pacientes) cada 28 días versus Placebo (43 pacientes).

Intestino delgado.

Bien diferenciados, $95 \%$ Ki 67 menor a $2 \%$.

Tumor funcionante y no funcionante. Síndrome carcinoide $38,8 \%$.

74,1\% tenía octreoscan positivo.

No especificado.

Tiempo a la progresión: 14,3 meses en rama de Octr versus 6 meses en rama placebo.

\section{CLARINET (204 pacientes)}

Lan $120 \mathrm{mg}$ (101 pacientes) versus Placebo (103 pacientes).

Páncreas (45\%), intestinal (36\%), colon (7\%), origen desconocido (13\%).

Bien y mod. diferenciados, Ki 67 menor a $10 \%$. 29,9\% Ki 67 3-10\%

Tumor no funcionante.

$100 \%$ tenía octreoscan positivo.

No enfermedad en progresión. Solo $5 \%$ con progresión.

Sobrevida libre de progresión no alcanzada en rama Lan versus 18 meses en rama placebo.

Estudios PROMID y CLARINET. ${ }^{121,122}$

de m-TOR, cuya vía de señalización intracelular implica activación de PI3K/Akt. Este estudio aleatorizado, fase III, incorporó a 302 pacientes de distintas localizaciones, estratificados según sitio, incluyendo tumores de origen gastrointestinal y broncopulmonar, así como tumores de origen desconocido. El RADIANT IV mostró beneficio en términos de SLP a favor de pacientes con TNE no funcionantes, 11 meses versus 3,9 meses (HR = 0,48 , IC $95 \%, 0,35-0,67, p<0,00001$ ), de forma independiente de la localización del tumor primario.

\section{Uso de radioligandos, lutecio $\left({ }^{177} \mathrm{Lu}\right)$}

El uso de radioligandos, o PRRT (Peptide Receptor Radionuclide Therapy), como se lo denomina en la literatura, ha mostrado beneficios en pacientes con diagnóstico de TNE de origen gastrointestinal, de acuerdo con los datos del único estudio aleatorizado que evaluó su eficacia. El estudio NETTER $1^{124}$ incluyó a 229 pacientes y utilizó ocreótido LAR dosis estándar más ${ }^{177} \mathrm{Lu}, 4$ aplicaciones IV, cada 8 semanas (rama experimental) versus ocreótido $60 \mathrm{mg}$ cada 28 días en pacientes que habían recibido previamente dosis estándar de octreótido.

En el análisis primario del estudio, no se había alcanzado la mediana de SLP en la rama experimental versus 8,4 meses en la rama de ocreótido $60 \mathrm{mg}$ cada 28 días (HR: 0,21; IC 95\%, 0,13-0,33, $p<0,001$ ). Se observó además una reducción del riesgo de muerte del $60 \%$, asociado al tratamiento con ${ }^{177} \mathrm{Lu}$, en el reporte inicial publicado, $(\mathrm{HR}=0,40$, IC $95 \%, p=0,004)$ con datos aún no maduros para el cálculo de la mediana de sobrevida global. De acuerdo al NETTER 1, el uso de ${ }^{177} \mathrm{Lu}$ debería pensarse en pacientes con TNE de origen intestinal, con Ki 67 menor al 20\%, con expresión de receptores de SST, que hayan progresado a terapia previa con base en a SST, sin tener en cuenta si es un tumor funcionante o no funcionante. Si bien el estudio no incluyó a pacientes con TNE de otras localizaciones, el principal biomarcador en este caso es la expresión de receptores de somatostatina más que la localización del tumor primario. La evidencia, en este caso, en cuanto al efecto de ${ }^{177} \mathrm{Lu}$ en TNE de otras localizaciones tiene un menor nivel de evidencia. ${ }^{125}$ 
En el ámbito local, existe experiencia con el uso de Ytrio 90 en el Instituto de Oncología Ángel H. Roffo. ${ }^{126}$ Los datos de 16 pacientes fueron presentados en el Congreso Anual de ENETS 2019, mostrando control de enfermedad en 6 a 37\% de los casos con sobrevida entre 26 y 53 meses.

\subsubsection{Tratamiento en TNE de origen pancreático}

Los tumores pancreáticos funcionantes (F p-TNE) pueden categorizarse en tres grupos: los gastrinomas, que son los más frecuentes, los insulinomas, considerados independientemente, $y$ todas las formas raras consideradas juntas y como una categoría separada. La mayoría de los p-TNE se presentan como tumores esporádicos (no hereditarios), aunque una proporción variable de los diferentes tumores funcionantes ocurren como parte de un síndrome hereditario.

NEM 1 sigue siendo la condición hereditaria más importante responsable del 20-30\% de los gastrinomas y de $<5 \%$ de los insulinomas o tumores pancreáticos funcionantes poco frecuentes.

\section{Tratamiento médico}

\section{Síndrome de Zollinger Ellison}

Los fármacos de elección son los inhibidores de bomba de protones (IBP) (una o dos veces al día). La vigilancia implica evaluar el control continuo de los síntomas, seguimiento de la deficiencia de vitamina B12 y no perder de vista que la hipomagnesemia es más frecuente en pacientes que toman IBP como un efecto de clase de fármaco. Los pacientes que se curan quirúrgicamente pueden continuar con hipersecreción de ácido gástrico y requerir monitoreo frecuente, y la mayoría $(60 \%)$ requiere drogas antisecretoras. ${ }^{73}$

\section{Insulinoma}

La cirugía sigue siendo el tratamiento de elección siempre que sea posible. No obstante, antes de la cirugía, los casos recurrentes y los pacientes con neoplasias malignas necesitan tratamiento médico. Además del tratamiento con diazóxido, se requieren colaciones pequeñas frecuentes, análogos de la somatostatina, aunque estos no siempre son eficaces para el control de hipoglucemia, porque inhiben el glucagón y por ende un mecanismo de contrarregulación, e inhibidores de mTOR (everolimus), que ha demostrado ser eficaz en controlar la hipoglucemia en un número creciente de reportes. El sunitinib también ha sido efectivo en algunos pacientes. ${ }^{73} \mathrm{El}$ tratamiento con PRRT o quimioembolización también pueden ayudar a controlar la hipoglucemia. ${ }^{87}$

\section{Tratamiento sistémico de los TNE pancreáticos}

Análogos de la somatostatina como terapia antitumoral versus vigilancia

Dos estudios de fase III controlados contra placebo han demostrado los efectos antitumorales de análogos de SST (octreótide y lanreótide) en los TNE gastrointestinales y pancreáticos bien diferenciados con Ki- $67<10 \%,{ }^{121,} 122$ independientemente del estatus funcional del TNE.

Recomendaciones: los a SST son el tratamiento sistémico de primera línea para TNE-GEP bien diferenciados, inoperables y avanzados con Ki-67 $<10 \%$. Previamente debe confirmarse la expresión de SSTR2 a través de octreoscan o PET/TC con ${ }^{68} \mathrm{Ga}$ antes del tratamiento basado en análogos de SST. ${ }^{124}$

Tanto ocreótido y lanreótido tienen una seguridad y eficacia similares. Se podría recomendar vigilancia en TNE bien diferenciados, preferiblemente en aquellos con enfermedad G1, no funcionante, de bajo volumen y oligosintomática. Los TNE G1 son indolentes y pueden estabilizarse durante meses o años sin tratamiento, como se observa en la mediana de sobrevida libre de progresión (SLP) en el grupo de placebo del estudio CLARINET. ${ }^{122}$ Además, no hay evidencia de que los análogos de SST tengan un impacto en la sobrevida global (SG) o en la calidad de vida en pacientes con tumores no funcionantes. ${ }^{121}$

\section{Interferón- $\alpha$}

A pesar de su perfil de toxicidad desfavorable, el interferón- $\alpha$ todavía se utiliza, y en muchos países de bajos recursos es uno de los pocos tratamientos disponibles para pacientes con enfermedad avanzada y síndrome carcinoide refractario. ${ }^{87}$ Varios estudios han demostrado que el interferón- $\alpha$ proporciona control tumoral, principalmente a través de la estabilización de la enfermedad y la respuesta sintomática en el síndrome carcinoide. Sin embargo, los estudios aleatorios no han demostrado que el interferón- $\alpha$ solo o combinado con a SST sea superior a la monoterapia. ${ }^{119,} 120$

Recomendaciones: el interferón- $\alpha$ puede usarse en casos de tumores neuroendocrinos bien diferenciados con progresión y/o resistentes a los análogos de SST, principalmente para control de síndrome carcinoide. ${ }^{87}$

\section{Quimioterapia para TNE bien diferenciados}

La quimioterapia, aunque se ha estudiado en un solo ensayo fase III, se considera un tratamiento eficaz para p-TNE G1 y G2, con tasas de respuesta del 30\% al 40\% con temozolomida y capecitabina, ${ }^{127}$ capecitabina y oxaliplatino, ${ }^{128}$ FOLFOX, dacarbazina o estreptozotocina sola 
o asociada con 5 Fluorouracilo (5FU). No se ha establecido el mejor régimen o el número de ciclos.

Se han estudiado los factores predictivos para las respuestas de quimioterapia. La deficiencia de metilguanilmetiltransferasa (MGMT) evaluada por IHQ o por metilación puede tener un papel predictivo para determinar la respuesta alquilante. ${ }^{129}$ Sin embargo, el mejor método de medición MGMT no ha sido determinado. El papel del Ki-67 como predictor de la respuesta a la quimioterapia en p-TNE bien diferenciados no está establecido, pero puede considerarse para la indicación de quimioterapia.

Recomendaciones: ${ }^{87}$

- Pacientes con TNE pancreáticos bien diferenciados, con progresión radiológica y/o sintomática durante el tratamiento con análogos de la somatostina.

- Regímenes sugeridos: capecitabina combinada con temozolomida u oxaliplatino, FOLFOX y estreptozotocina con o sin $5 \mathrm{FU}$.

- El aumento de la expresión de Ki-67 puede usarse para recomendar quimioterapia en $\mathrm{p}-\mathrm{TNE}$ bien diferenciados.

- La expresión de MGMT no debe guiar el uso de temozolomida/dacarbazina. ${ }^{129}$

\section{Terapia dirigida en TNE pancreáticos bien dife- renciados: sunitinib y everolimus}

El estudio RADIANT- ${ }^{130}$ controlado con placebo, de fase III, en pacientes con TNE pancreáticos con enfermedad avanzada, mostró una mejor SLP, a favor de everolimus, con una mediana de sobrevida global de 11 versus 4,6 meses ( $\mathrm{HR}=0,35$; IC 95\%, 0,27-0,45; $p<0,0001)$.

Sunitinib es un inhibidor oral de los receptores de tirosina quinasa PDGFR, VEGFR y c-KIT, y ha mostrado una mayor eficacia en un estudio fase III controlado con placebo (tumores mayormente bien diferenciados) y demostró la tasa media de OS de 11,4 versus 5,5 meses $(\mathrm{HR}=0,42$; IC 95\%, 0,26-0,66; $p<0,001) .{ }^{131}$ La elección entre ambos fármacos debe considerar sus perfiles de toxicidad. Los eventos adversos graves (grado 3 y 4) más comúnmente asociados con sunitinib fueron neutropenia (12\%), hipertensión (10\%) y síndrome manos-pie $(6 \%)$, mientras que everolimus provocó comúnmente estomatitis (7\%), anemia $(6 \%)$ e hiperglucemia $(5 \%) .{ }^{130,131}$

Everolimus y sunitinib se recomiendan para p-TNE funcionantes o no funcionantes avanzados. Ambos medicamentos pueden usarse en terapia de primera línea o luego de la progresión a análogos de la somatostatina y/o quimioterapia. Everolimus y sunitinib también pueden combinarse con análogos de la somatostatina en el caso de tumores funcionantes. En los insulinomas metastásicos, el everolimus es el fármaco de elección. ${ }^{132}$

\section{Radioisótopos}

El tratamiento con PRRT utilizando ${ }^{90} \mathrm{Y}-\mathrm{DOTA}-$ TOC o ${ }^{177} \mathrm{Lu}$-DOTATATE, incluido $\mathrm{p}$-TNE con metástasis a distancia, se puede considerar en ambos TNE funcionantes y no funcionantes con expresión alta y homogénea de receptores de somatostatina, independientemente del sitio del tumor primario. Sobre la base de los resultados de estudios fase II, más de 1000 pacientes han sido tratados con PRRT en Europa, con respuestas objetivas completas o parciales en hasta un $30-40 \%$ y una sobrevida libre de progresión de 17-40 meses. ${ }^{133}$

Las contraindicaciones para PRRT incluyen embarazo, trastornos psiquiátricos graves, insuficiencia renal moderada o grave y baja reserva medular. ${ }^{133}$

Se recomienda ${ }^{177} \mathrm{Lu}$ para TNE de origen gastrointestinal avanzados bien diferenciados. No se ha establecido el mejor momento para administrar ${ }^{177} \mathrm{Lu}$, aún se requieren estudios de secuenciación, sobre todo para establecer, en el caso de p-TNE progresados a análogos de la somatostatina, si realizar ${ }^{177} \mathrm{Lu}$ luego de terapias target o previo a estas. Es necesario confirmar la expresión de SSTR2 mediante octreoscan o PET/TC con ${ }^{68} \mathrm{Ga}$ antes de PRRT. ${ }^{132,133}$

\section{Carcinomas neuroendocrinos G3}

Los CNE G3, es decir de alto grado y con histología de poco diferenciados, son poco frecuentes y se asocian con un pronóstico desfavorable, con una SG media de menos de un año. ${ }^{134}$ Los estudios retrospectivos sugieren que la SG aumenta con la terapia adyuvante. ${ }^{135}$ Para la enfermedad metastásica, la quimioterapia basada en platino se considera el tratamiento estándar, sin diferencias clínicamente relevantes aparentes entre el cisplatino y el carboplatino. ${ }^{136}$ Recientemente, las series retrospectivas han demostrado que los tumores G3 pueden presentar histologías de tumores bien diferenciados y que este subgrupo tiene un índice proliferativo más bajo y un mejor pronóstico en comparación con los carcinomas poco diferenciados. ${ }^{137,138}$

Un estudio europeo retrospectivo y multicéntrico mostró que el índice Ki-67 más alto se asocia con una mejor respuesta a la quimioterapia basada en platino. ${ }^{136}$ Sin embargo, no se encontró que el Ki-67 sea un predictor para la respuesta a la quimioterapia en otros estudios. ${ }^{138}$ 


\section{G3 localizado}

En CNE G3 resecable, podría ofrecerse cirugía oncológica y también podría considerarse un tratamiento definitivo con quimioterapia a base de platino combinada con radioterapia para tumores localmente avanzados o no resecables. La quimioterapia adyuvante con cisplatino (o carboplatino), asociada con etopósido o irinotecán, durante 4 a 6 ciclos puede considerarse en pacientes con buen estado funcional luego de la resección quirúrgica. ${ }^{135}$
Tratamiento de la enfermedad metastásica: cisplatino (o carboplatino) asociado con irinotecán o etopósido para el tratamiento de primera línea. ${ }^{134,136}$ Los regímenes basados en temozolomida o en oxaliplatino pueden usarse en los tumores bien diferenciados G3. La temozolomida o la dacarbazina pueden usarse como tratamientos de segunda línea después de los regímenes de platino. ${ }^{139}$

3.3.3 Algoritmo final sobre tratamiento sistémico (Figura 6 y 7 ).

Figura 6. Tumores neuroendocrinos bien diferenciados, G1, G2.
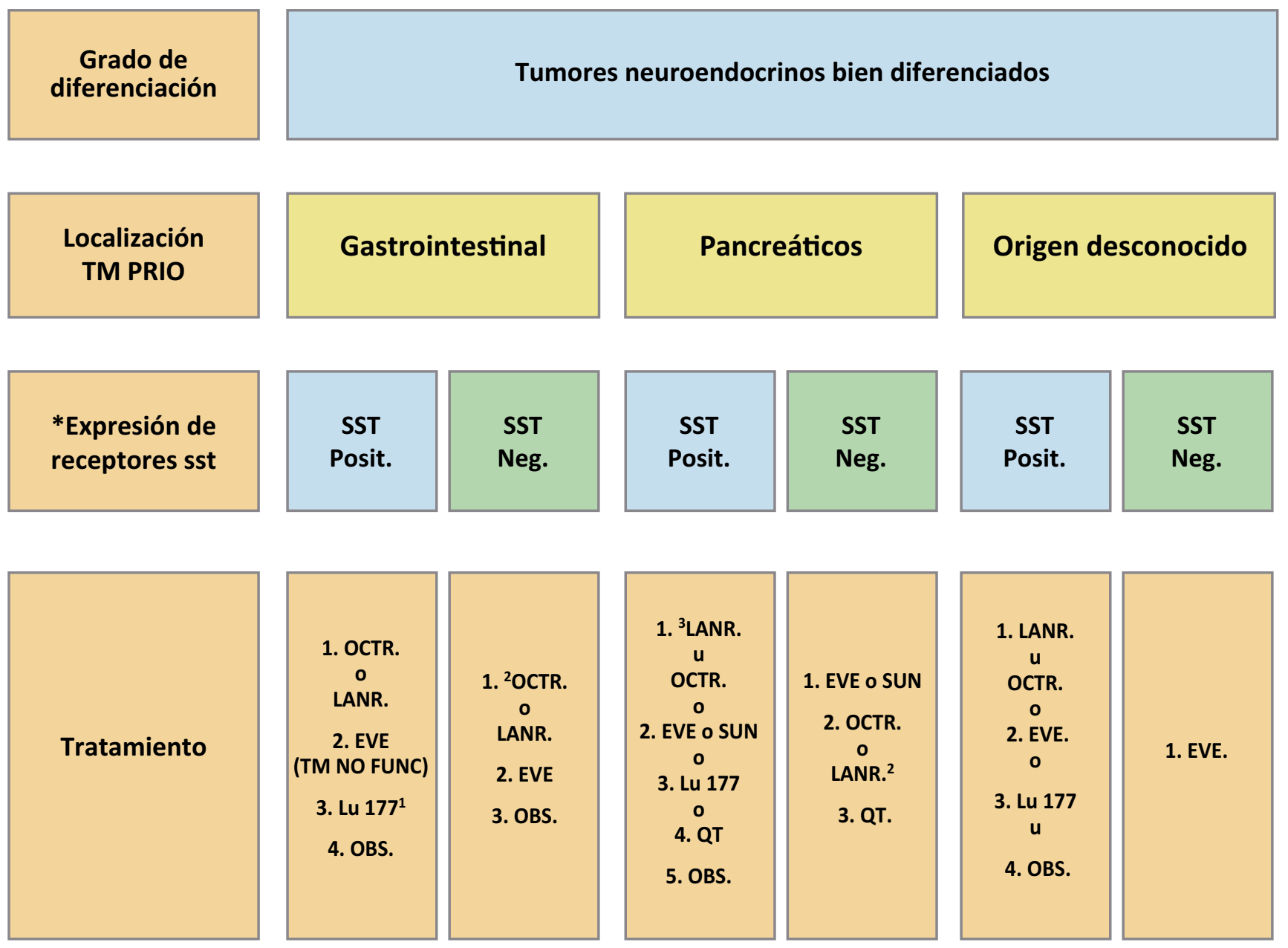

\footnotetext{
* La expresión de receptores con evidencia a través de octreoscan, con In 111 o Tecnecio 99m, o bien Ga 68 (el estudio con Galio 68 tiene mayor sensibilidad y especificidad).

${ }^{1}$ Lu 177 no aprobado en la Argentina. Eventual aplicación a través de uso compasivo. Experiencia local con Ytrio 90.

2 PROMID y CLARINET han incluido pacientes con estatus de receptores de SST negativo o desconocido.

${ }^{3}$ La decisión en cuanto a SST versus terapia blanco (EVE o SUN) y QT (quimioterapia) en los TNE pancreáticos depende de variables clínicas, como volumen de enfermedad, presencia de síntomas y velocidad de progresión.
} 
Figura 7. Tumores neuroendocrinos de alto grado definidos como G3.
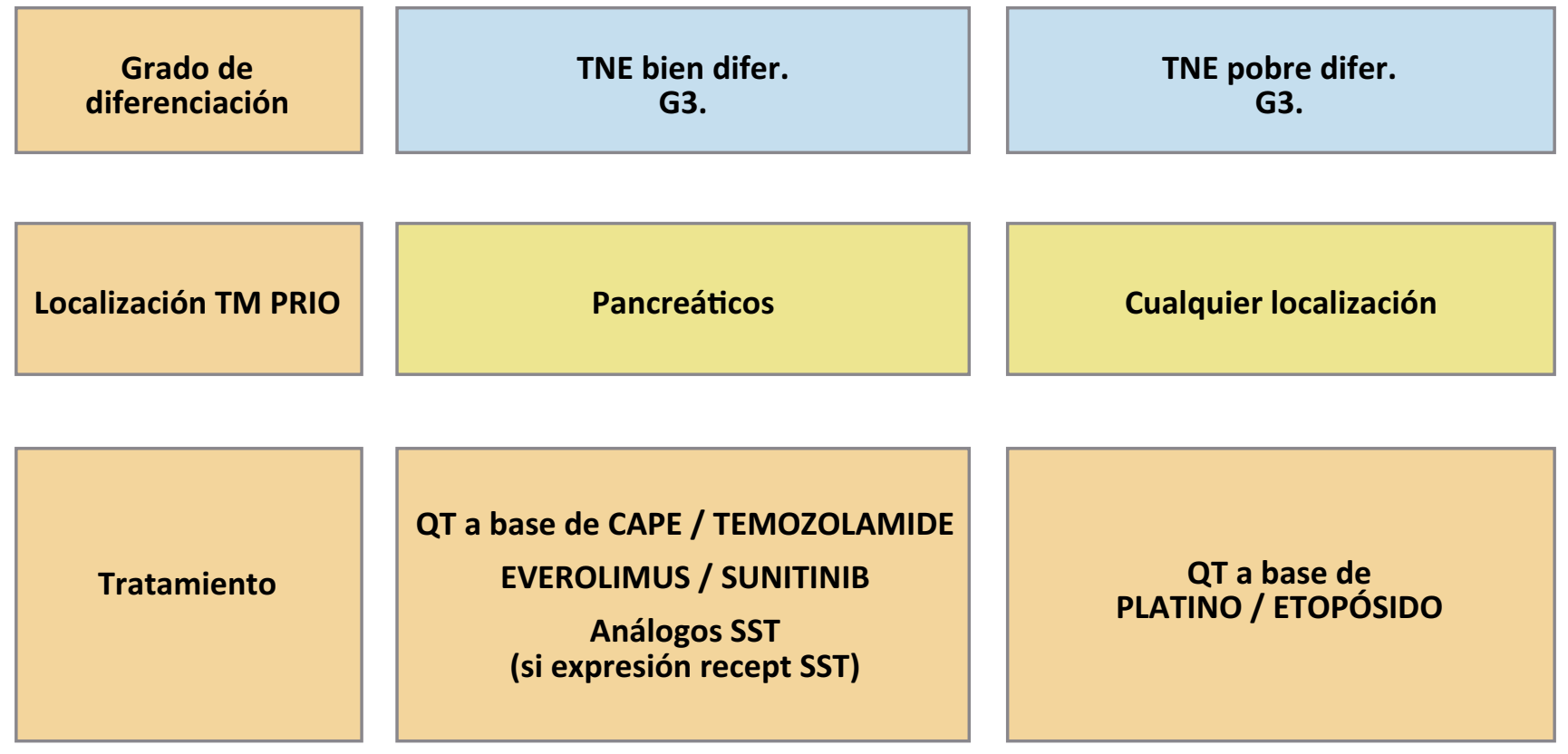

TNE pobre difer.

G3.

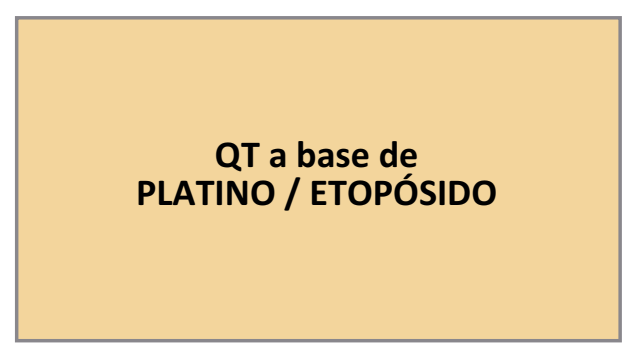

\section{Conflictos de Interés:}

Este documento fue realizado de forma independiente sin aporte alguno por parte de la industria farmacéutica.

Sin Conflictos de Interés:

Gabriela Acosta Haab; Irene Armas; Gabriel Bruno; Ana Cabanne; Enzo Domenichini; Agustin Falco; Julia Ismael; José Lastiri; Susana Lupi; Fernando Losada Lopez; Patricio Méndez; Lisandro Paganini; Diego Ramisch; Sonia Traverso.

Potenciales Conflictos de Interés:

\begin{tabular}{|c|c|c|c|}
\hline NOMBRE AUTOR & SPEAKER (De qué laboratorio) & $\begin{array}{l}\text { RECIBIÓ O RECIBE GRANTS } \\
\text { (De qué laboratorio) }\end{array}$ & $\begin{array}{l}\text { EMPLEADO } \\
\text { (De qué laboratorio) }\end{array}$ \\
\hline Juan Manuel O'Connor & Novartis/Sanofi/Bayer/Servier/Merck & Novartis/Sanofi/Merck/Bayer & No relación laboral \\
\hline Susana Belli & Novartis/Sanofi & Novartis/Sanofi & No relación laboral \\
\hline Karina Danilowicz & Novartis/Sanofi & Novartis/Sanofi & No relación laboral \\
\hline Rubén Rampa & Ninguno & Ninguno & $\begin{array}{l}\text { Director Médico } \\
\text { Lab. Microsules }\end{array}$ \\
\hline Rizzolo Mariana & Novartis/Sanofi & Novartis/Sanofi & No relación laboral \\
\hline Pablo Sanchez & Novartis/Merck/Bayer & Novartis/Merck & No relación laboral \\
\hline Julieta Tkatch & Ninguno & Novartis/Sanofi & No relación laboral \\
\hline Guillermo Méndez & Novartis/Sanofi/Bayer/Merck & Novartis/Merck/Bayer/Roche & No relación laboral \\
\hline Mariano Dioca & Novartis/Sanofi/Bayer/Servier/Merck & Novartis/Sanofi & No relación laboral \\
\hline
\end{tabular}




\section{Referencias}

1. Hallet J, Law CH, Cukier M, et al. Exploring the rising incidence of neuroendocrine tumors: a population-based analysis of epidemiology, metastatic presentation, and outcomes. Cancer 2015; 121: 589-597.

2. Dasari A, Shen C, Halperin D, Zhao B, Zhou S, Xu Y, et al. Trends in the incidence, prevalence, and survival outcomes in patients with neuroendocrine tumors in the United States. s.l.: JAMA Oncol 2017; 3: 1335-1342.

3. Halperin DM, Shen C, Dasari A, et al. Frequency of carcinoid syndrome at neuroendocrine tumour diagnosis: a populationbased study. Lancet Oncol 2017; 18: 525-534.

4. O'Connor JM, Marmisolle F, Bestani C, Pesce V, Belli S, Dominichini E, et al. Observational Study of patient with gastoenteropancreatic and bronchial neuroendocrine tumors in Argentina: Results from the large database of a multidisciplinary group clinical multicenter study. Molecular Clinical Oncology 2014; 2: 673-684.

5. Moncet D, Flores M, Armanelli E, Carranza O, Zoppi J, Descalzo J, Isaac GB. Tumores neuroendocrinos: Experiencia interdisciplinaria del Hospital Privado de Comunidad. Rev Argent Endocrinol Metab 2019; 56.

6. Crona J, Skogseid B. Genetics of neuroendocrine tumors. European Journal of Endocrinology 2016; 174: R275-R290.

7. Thakker RV, Newey PJ, Walls GV, Bilezikian J, Dralle H, Ebeling PR, Melmed S, Sakurai A, Tonelli F, Brandi ML. Clinical Practice Guidelines for Multiple Endocrine Neoplasia Type 1 (MEN1). J Clin Endocrinol Metab 2012; 97: 2990-3011.

8. Ito T, Igarashi H, Jensen RT. Pancreatic neuroendocrine tumors: clinical features, diagnosis and medical treatment: advances. Best practice and research. Clinical gastroenterology 2012; 26: 737-753.

9. Maher ER, Yates JR, Harries R, Benjamin C, Harris R, Moore AT, Ferguson-Smith MA. Clinical features and natural history of Von Hippel-Lindau disease. Q J Med 1990; 77: 1151-1163.

10. Jozwiak J, Jozwiak S, Wlodarski P. Possible mechanisms of disease development in tuberous sclerosis. Lancet Oncol 2008; 9 (1): 73-79.

11. Triponez F, Goudet P, Dosseh D, Cougard P, Bauters C, Murat A, Cadiot G, Niccoli-Sire P, Calender A, Proye CA; Group French Endocrine Tumor Study. Is surgery beneficial for MEN1 patients with small $(<$ or $=2 \mathrm{~cm})$, nonfunctioning pancreaticoduodenal endocrine tumor. World Journal of Surgery 2006; 30: 654-662.

12. Sakurai A, Katai M, Yamashita K, Mori J, Fukushima Y, Hashizume K. Long-term follow-up of patients with multiple endocrine neoplasia type 1. Endocrine journal 2007; 54: 295-302.

13. Nell S, Verkooijen HM, Pieterman CRC, de Herder WW, Hermus AR, Dekkers OM, Van der Horst-Schrivers AN, Drent ML, Bisschop PH, Havekes B, Borel Rinkes IHM, Vriens MR, Valk GD. Management of MEN1 Related Nonfunctioning Pancreatic NETs: A Shifting Paradigm: Results from the DutchMEN1 Study Group. Annals of Surgery 2018; 267: 1155-1160.

14. Maher ER, Neumann HP, Richard S. Von Hippel-Lindau disease: a clinical and scientific review. Eur J Hum Genet 2011; 19 (6): 617-623.
15. Crespigio J, Berbel L, Diaz M, Berbel R, Pereira S, Pignatelli T, Mazzuco. Von Hippel-Lindau disease: a single gene, several hereditary tumors. J Endocrinol Invest 2017.

16. Northrup H, Krueger D and on behalf of the International Tuberous Sclerosis Complex Consensus Group. Tuberous Sclerosis Complex Diagnostic Criteria Update: Recommendations of the 2012 International Tuberous Sclerosis Complex Consensus Conference. Pediatr Neurol 2013; 49 (4): 243-254.

17. Dworakowska D, Grossman AB. Are neuroendocrine tumours a feature of tuberous sclerosis? A systematic review. Endocr Relat Cancer 2009; 16: 45-58.

18. Rindi G, Klimstra DS, Abedi-Ardekani B, Asa SL, Bosman FT, Brambilla E, Busam KJ, de Krijger RR, Dietel M, El-Naggar AK, Fernandez-Cuesta L, Klöppel G, McCluggage WG, Moch H, Ohgaki H, Rakha EA, Reed NS, Rous BA, Sasano H, Scarpa A, Scoazec JI, Travis WD. A common classification framework for neuroendocrine neoplasms: an International Agency for Research on Cancer (IARC) and World Health Organization (WHO) expert consensus proposal. Modern Pathology 2018; 31: 1770-1786.

19. Woischke C, Schaaf CW, Yang HM, Vieth M, Veits L, Geddert $\mathrm{H}$, et al. In-depth mutational analyses of colorectal neuroendocrine carcinomas with adenoma or adenocarcinoma components. Mod Pathol 2017; 30: 95-103.

20. Ali AS, Gronberg M, Federspiel B, Scoazec JY, Hjortland GO, Gronbaek H. Expression of p53 protein in high-grade gastroenteropancreatic neuroendocrine carcinoma. PLoS ONE 2017; 12: e0187667.

21. Lloyd RV, Osamura RY, Klöppel G, Rosai J. WHO Classification of Tumours of Endocrine Organs. Lyon: $4^{\circ}$ ed. Lyon: International Agency for Research on Cancer, 2017.

22. Klimstra DS, Klopper G, La Rosa S, Rindi G. WHO classification of tumours of the digestive system. s.l.: 2019; 5 .

23. Klöppel G. s.l.: Neuroendocrine Neoplasms: Dichotomy, Origin and Classifications. Visc Med 2017; 33: 324-330.

24. Colegio Americano de Patólogos. Protocolo de estudio de especímenes de pacientes con tumores neuroendocrinos del Colegio Americano de Patólogos (CAP). https://www.cap.org. Cancer Protocol Templates. Endocrine. Appendix NET (v4.0.0.1), Colon NET (v4.0.0.1), Duodenum and Ampulla NET (v1.0.0). [En línea] Junio de 2017. [Citado el: 20 de 01 de 2020.] https://www. cap.org.

25. Brierley JD, Gospodarowicz MK, Wittekind C. TNM Classification of Malignant Tumours. Eighth edition s.l.: Union for International Cancer Control, 2017.

26. Ganeshan D, Bhosale P, Yang T, et al. Imaging features of carcinoid tumors of the gastrointestinal tract. AJR Am J Roentgenol 2013; 201: 773-786.

27. Sahani D, Bonaffini P, Fernández del Castillo C, Blake M. Gastroenteropancreatic Neuroendocrine Tumors: Role of Imaging in Diagnosis and Management. Radiology 2013; 266: 38-61. 10.1148/radiol.12112512.

28. Bonekamp D, Raman S, Horton K, Fishman E. Role of computed tomography angiography in detection and staging of small bowel carcinoid tumors. World Journal of Radiology 2015; 7: 220-235. 10.4329/wjr.v7.i9.220. 
29. Dumlu E, Karakoc D, Özdemir A. Nonfunctional Pancreatic Neuroendocrine Tumors: Advances in Diagnosis, Management, and Controversies. International surgery 2015; 100. 10.9738/ INTSURG-D-14-00204.1.

30. Cui Y, Li ZW, Li XT, Gao SY, Li Y, Li J, Zhu HC, Tang L, Cao $\mathrm{K}$, Sun YS. Dynamic enhanced CT: Is there a difference between liver metastases of gastroenteropancreatic neuroendocrine tumor and adenocarcinoma. Oncotarget 2017; 8: 10.18632/oncotarget.22554.

31. Zamboni G, Ambrosetti M, Zivelonghi C, Lombardo F, Butturini G, Cingarlini S, Capelli P, Pozzi Mucelli R. Solid non-functioning endocrine tumors of the pancreas: Correlating computed tomography and pathology. HPB 2017; 19.

32. Giesel FL, Kratochwil C, Mehndiratta A, et al. Comparison of neuroendocrine tumor detection and characterization using DOTATOC-PET in correlation with contrast enhanced CT and delayed contrast enhanced MRI. Eur J Radiol 2012; 81: 2820-2825.

33. Dromain C, de Baere T, Lumbroso J, et al. Detection of liver metastases from endocrine tumors: a prospective comparison of somatostatin receptor scintigraphy, computed tomography, and magnetic resonance imaging. J Clin Oncol 2005; 23: 70-78.

34. Kamaoui I, De-Luca V, Ficarelli S, et al. Value of CT enteroclysis in suspected small-bowel carcinoid tumors. AJR Am J Roentgenol 2010; 194: 629-633.

35. Van Weyenberg SJ, Meijerink MR, Jacobs MA, et al. MR enteroclysis in the diagnosis of smallbowel neoplasms. s.l.: Radiology 2010; 254: 765-773.

36. Lardière-Deguelte $S$, De Mestier L, Appéré F, et al. Toward a preoperative classification of lymph node metastases in patients with small intestinal neuroendocrine tumors in the era of intestinal-sparing surgery. Neuroendocrinology 2016; 103: 552-559.

37. Kocha W, Maroun J, Kennecke H, et al. Consensus recommendations for the diagnosis and management of well-differentiated gastroenterohepatic neuroendocrine tumours: a revised statement from a Canadian National Expert Group. Curr Oncol 2010; 17: 49-64.

38. Rockall AG, Reznek RH. Imaging of neuroendocrine tumours (CT/MR/US). Best Pract Res Clin Endocrinol Metab 2007; 21 : 43-68.

39. Sundin A, Vullierme MP, Kaltsas G, et al. ENETS Consensus Guidelines for the Standards of Care in Neuroendocrine Tumors: radiological examinations. Neuroendocrinology 2009; 90 : 167-183.

40. Tsoli M, et al. Current best practice in the management on neuroendocrine tumors. Ther Adv Endocrinol Meta 2019; 10: 1-18.

41. Hope TA, Bergsland EK, Bozkurt MF, et al. Appropriate Use Criteria for Somatostatin Receptor PET Imaging in Neuroendocrine Tumors. The Journal of Nuclear Medicine 2018; 59: 66-74.

42. Buchmann I, Henze M, Engelbrecht S, et al. Comparison of 68Ga-DOTATOC PET and 111In-DTPAOC (Octreoscan) SPECT in patients with neuroendocrine tumours. Eur J Nuc Med Mol Imaging 2007; 34: 1617-1626.

43. Bodei L, Ambrosini V, Herrmann K, et al. Current Concepts in 68Ga-DOTATATE Imaging of Neuroendocrine Neoplasms: Interpretation, Biodistribution, Dosimetry, and Molecular Strategies. J Nucl Med 2017; 58: 1718-1726.
44. Panagiotidis E, Alshammari A, Michopoulou S, et al. Comparison of the Impact of 68Ga-DOTATATE an 18F-FDG PET/CT on Clinical Management in Patients with Neuroendocrine Tumors. J Nucl Med 2017; 58: 91-96.

45. Morgat C, et al. Evaluation of 68GA-DOTATOC PET/CT for the detection of duodenopancreatic neuroendocrine tumors in patients with MEN1. Eur J Nucl Med Mol Imaging 2016; 43: 1258-1266.

46. Deroose I, Hindié E, Kebebew E, et al. Molecular Imaging of Gastroenteropancreatic Neuroendocrine Tumors: Current Status and Future Directions. J Nucl Med 2016; 57: 1949-1956.

47. González Flores E, Serrano E Sevilla I, et al. SEOM clinical guidelines for the diagnosis and treatment of gastroenteropancreatic and bronchial neuroendocrine neoplasms (NEN). Clinical and Translational Oncology 2019; 21: 55-63.

48. Hindié E. The NETPET Score: Combining FDG and Somatostatin Receptor Imaging for Optimal Management of Patients with Metastatic Well-Differentiated Neuroendocrine tumors. Theranostics 2017; 7: (5): 1159-1163.

49. Kayani I, Bomanji JB, Groves A, et al. Functional imaging of neuroendocrine tumors with combined PET/CT using 68GaDOTATATE (DOTA-DPhe1, Tyr3-octreotate) and 18F-FDG. Cancer 2008; 112 (11): 2447-2455.

50. Sundin A, Arnold R, Baudin E, Cwikla J, Eriksson B, Fanti S, Fazio N, Giammarile F, Hicks R, Kjaer A, Krenning E, Kwekkeboom D, Lombard-Bohas C, O 'Connor JM, O 'Toole D, Rockall A, Wiedenmann B, Valle J, Vullierme MP all other Antibes Consensus Conferenc. ENETS Consensus Guidelines for the Standards of Care in Neuroendocrine Tumors: Radiological, Nuclear Medicine \& Hybrid Imaging. Neuroendocrinology 2017; 105 (3): 212-244.

51. Bozkurt MF, Virgolini I, Balogova S, Rubello D, Decristoforo C, Ambrosini V, Kjaer A, Delgado-Bolton R, Kunikowska J, Oyen WJG, Chiti A, Giammarile F, Sundin A. Guideline for PET/CT imaging of neuroendocrine neoplasms with 68Ga-DOTA-conjugated somatostatin receptor targeting peptides and F-DOPA. Eur J Nucl Med Mol Imaging 2017; 44: 1588-1601.

52. Fottner C, Ferrata M, Weber M. Hormone secreting gastro-entero-pancreatic neuroendocrine neoplasias (GEP-NEN): When to consider, how to diagnose? Rev Endocr Metab Disord 2017; 18 : 393-410.

53. Meijer WG, Kema IP, Volmer M, et al. Discriminating capacity of indole markers in the diagnosis of carcinoid tumors. Clin Chem 2000; 46: 1588-1596.

54. Adaway JE, Dobson R, Walsh J, et al. Serum and plasma 5-hydroxyindoleacetic acid as an alternative to 24-h urine 5-hydroxyindoleacetic acid measurement. Ann Clin Biochem 2016: 554-560.

55. Niederle B, Pape UF, Costa F and all other Vienna Consensus Conference participants. ENETS Consensus Guidelines Update for Neuroendocrine Neoplasm of the jejunum and ileum. Neuroendocrinology 2016; 103: 125-138.

56. Ramage JK, Davies AH, Ardill J, et al. Guidelines for the management of gastroenteropancreatic neuroendocrine (including carcinoid) tumours (NETs). UKNETwork for Neuroendocrine Tumours. s.l.: Gut 2012; 61: 6-32. 
57. Delle Fave G, Fazio N, Rinzivillo M, et al. Linee Guida Neoplasie Neuroendocrine. Associazione Italiana di Oncologia Medica - Italian Association for Neuroendocrine Tumours, 2018.

58. Cryer PE, et al. Evaluation and management of adult hypoglycemic disorders: an Endocrine Society Clinical Practice Guideline. J Clin Endocrinol Metab 2009; 94: 709-728.

59. Falconi M, Eriksson B, Kaltsas G, Bartsch D, Capdevila J, Koskudla B, Kwekkeboom D, Rindi G, Kloppel G, Reed N, et al. Consensus guidelines update for the management of functional p-NETs (F-p-NETs) and non-functional p-NETs (NF-p-NETs). Neuroendocrinology 2016; 103: 153-171.

60. Kindmark H, Sundin A, Granberg D, et al. Endocrine pancreatictumors with glucagon hypersecretion: a retrospective study of 23 cases during 20 years. Med Oncol 2007; 24: 330-337.

61. Yang X, Yang Y, Li Z, et al. Diagnostic Value of CirculatingChromogranin A for Neuroendocrine Tumors: A Systematic Reviewand Meta-Analysis. PLOS ONE 2015; 20.

62. Rossi RE, Garcia-Hernandez J, Meyer T, et al. Chromogranin Aas a predictor of radiological disease progression in neuroendocrinetumours. Ann Transl Med 2015; 3: 118-225.

63. Belli SH, Oneto A, Aranda C, et al. Chromogranin A as a biochemical marker for the management of neuroendocrine tumors: a multicenter study developed in Argentina. Acta Gastroenterol Latinoam 2009; 39: 184-189.

64. Sorbye H, Welin S, Langer SW, et al. Predictive and prognostic factors for treatment and survival in 305 patients with advanced gastrointestinal neuroendocrine carcinoma (WHO G3): theNORDIC NEC study. Ann Oncol 2013; 24: 152-160.

65. Korse CM, Taal BG, Vincent A, et al. Choice of tumour markers in patients with neuroendocrine tumours is dependent on thehistological grade. A marker study of Chromogranin A, Neuron specific enolase, Progastrin-releasing peptide and cytokeratin fragments. Eur J Cancer 2012; 48 (5): 662-671.

66. Baudin E, Gigliotti A, Ducreux M, et al. Neuron-specific enolase and chromogranin A as markers of neuroendocrine tumours. British Journal of Cancer 1998; 78: 1102.

67. Isgrò MA, Bottoni P, Scatena R. Neuron-Specific Enolase as a Biomarker: Biochemical and Clinical Aspects. Adv Exp Med Biol 2015; 867: 125-143.

68. Malczewska A, Witkowska M, Makulik K, et al. NETest liquid biopsy is diagnostic of small intestine and pancreatic neuroendocrine tumors and correlates with imaging. Endocrine Connections 2019; 8: 442-453.

69. Akirov A, Larouche V, Alshehri S, Asa SL, Ezzat S. Treatment Options for Pancreatic Neuroendocrine Tumors. Cancers (Basel) 2019; 11(6): E828.

70. Crippa S, Partelli S, Zamboni G, Scarpa A, Tamburrino D, Bassi $\mathrm{C}$, Pederzoli P, Falconi M. Incidental diagnosis as prognostic factor in different tumor stages of nonfunctioning pancreatic endocrine tumors. Surgery 2014; 155: 145-153.

71. Gaujoux S, Partelli S, Maire F, D’Onofrio M, Larroque B, Tamburrino D, Sauvanet A, Falconi M, Ruszniewski P. Observational study of natural history of small sporadic nonfunctioning pancreatic neuroendocrine tumors. J Clin Endocrinol Metab 2013; 98: 4784-4789.
72. Belotto M, Crouzillard B, Araujo K, Peixoto R. Pancreatic Neuroendocrine tumors: Surgical Resections. Arq Bras Cir Dig 2019; 32 (1): e1428.

73. Falconi M, Eriksson B, Kaltsas G, et al. Consensus guidelines update for the management of functional p-NET (F-p-NET) and non-functional p-NET (NF-p-NET). Neuroendocrinology 2016; 103: 153-171.

74. Öberg K, Knigge U, Kwekkeboom D, et al. Neuroendocrine gastro-entero-pancreatic tumors: ESMO. Clinical Practice Guidelines for diagnosis treatment and follow-up 2012; 23 (7): 124-130.

75. Shah M, Goldner W, Halfdanarson T, Bergsland E, Berlin J, Halperin D, Chan J, Kulke M, Benson A, Blaszkowsky L, et al. NCCN Clinical Practice Guidelines in Oncology: Neuroendocrine and Adrenal Tumors. J Natl Compr Cancer Netw 2018; 16: 693-702.

76. Collard M, Marchese T, Guedj N, Cauchy F, Chassaing C, Ronot M, Dokmak S, Soubrane O, Sauvanet A. Is Routine Splenectomy Justified for All Left-Sided Pancreatic Cancers? Histological Reappraisal of Splenic Hilar Lymphadenectomy. Ann Surg Oncol 2019; 26: 1.

77. Finkelstein P, Sharma R, Picado O, Gadde R, Stuart H, Ripat C, Livingstone AS, Sleeman D, Merchant N, Yakoub D. Pancreatic Neuroendocrine Tumors (panNETs): Analysis of Overall Survival of Nonsurgical Management Versus Surgical Resection. J Gastrointest Surg 2017; 21 (5): 855-866.

78. Feng T, Lv W, Yuan M, Shi Z, Zhong H, Sunbin Ling S. Surgical resection of the primary tumor leads to prolonged survival in metastatic pancreatic neuroendocrine carcinoma. World Journal of Surgical Oncology 2019; 17: 54.

79. Ye H, Xu HL, Shen Q, Zheng Q, Chen P. Palliative Resection of Primary Tumor in Metastatic Nonfunctioning Pancreatic Neuroendocrine Tumors. J Surg Res 2019, abril 25. pii: S00224804(19)30190-8.

80. Janson ET, Sorbye H, Welin S, et al. Nordic Guidelines 2010 for diagnosis and treatment of gastroenteropancreatic neuroendocrine tumours. Acta Oncol 2010; 49 (6): 740-756.

81. Jensen RT, et al. ENETS Consensus Guidelines for the management of patients with digestive neuroendocrine neoplasms: functional pancreatic endocrine tumor syndromes. Neuroendocrinology 2012; 95 (2): 98-119.

82. Singh S, Asa S, Dey C, Kennecke H, Laidley D, Law C, Asmis T, Chan D, Ezzat S, Goodwin R, Mete O, Pasieka J, Rivera J, Wong R, Segelov E, Rayson D. Diagnosis and Management of Gastrointestinal Neuroendocrine Tumors: An Evidence-Based Canadian Consensus. Cancer Treat Rev 2016; 47: 32-45.

83. Pironi L, Arends J, Baxter J, Bozzetti F, Burgos Peláez R, Cuerda C, Forbes A, Gabe S, Gillanders L, Holst M, Bekker Jeppesen P, Joly F, Kelly D, Klek S, Irtun O, Damink SW, Panisic M, Rasmussen HH, Staun M, Szczepanek K, Van Gossum A, Wanten G, Schneider. The Home Articial Nutrition \& Chronic Intestinal Failure and the Acute Intestinal Failure Special Interest Groups osf ESPEN. Clinical Nutrition 2016; 35: 247-307.

84. Gondolesi G, Doeyo M, Echevarria C, Lobos F, Rubio S, Rumbo C, Ramisch D, Crivelli A, Barros Schelotto P, Solar H. Results of Surgical and Medical Rehabilitation for Adult Patients with Type III Intestinal Failure in a Comprehensive Unit Today: Building a New Model to Predict Parenteral Nutrition Independency. Journal of Parenteral and Enteral Nutrition 2019; 111: 8. 
85. Ramage JK, De Herder WW, Delle Fave G, et al. Vienna Consensus Conference participants. ENETS consensus guidelines update for colorectal neuroendocrine neoplasms. Neuroendocrinology 2016; 103: 139-143.

86. Fields A, Saadat L, Scully R, Davids J, Goldberg J, Bleday R, Melnitchouk N. Local Excision Versus Radical Resection for 1 to $2 \mathrm{~cm}$ Neuroendocrine Tumors of the Rectum: A National Cancer Database Analysis. Dis Colon Rectum 2019; 62: 417-421.

87. Pavel M, O’Toole D, Costa F, Capdevila J, Gross D, Kianmanesh R, Krenning E, Knigge U, Salazar R, Pape U-F, Öberg K. Consensus Guidelines update for the management of distant metastatic disease of intestinal, pancreatic, bronchial neuroendocrine neoplasms (NEN) and NEN unknown primary site. Vienna Consensus Conference participants ENETS. Neuroendocrinology 2016; 103 (2): 172-185.

88. Zhang XF, Beal F, Weiss M, Aldrighetti L, Poultsides G, Bauer T, Fields R, Shishir K. Timing of disease occurrence and hepatic resection on long-term outcome of patients with neuroendocrine liver metastasis. J Surg Oncol 2017: 1-11.

89. Frilling A, Modlin IM, Kidd M, Russell C, Breitenstein S, Salem R, Kwekkeboom D, Lau WY, Klersy C, Vilgrain V, Davidson B, Siegler M, Caplin M, Solcia E, Schilsky R; Working Group on Neuroendocrine Liver Metastases. Recommendations for management of patients with neuroendocrine liver metastases. Lancet Oncol 2014; 15 (1): e8-21.

90. Mayo SC, Herman JM, Cosgrove D, Bhagat N, Kamel I, Geschwind JF, Pawlik TM. Emerging approaches in the management of patients with neuroendocrine liver metastasis: role of liver-directed and systemic. J Am Coll Surg 2013; 216 (1): 123-134.

91. Sarmiento JM, Heywood G, Rubin J, Ilstrup DM, Nagorney DM, Que FG. Surgical treatment of neuroendocrine metastases to the liver: a plea for resection to increase survival. J Am Coll Surg 2003; 197 (1): 29-37.

92. Sørbye H, Westre B, Horn A. Curative surgery after neoadjuvant chemotherapy in metastatic poorly differentiated neuroendocrine carcinoma. European Journal of Surgical Oncology (EJSO) 2007; 33 (10): 1209-1210.

93. Sarmiento JM, Que FG. Hepatic surgery for metastases from neuroendocrine tumors. Surg Oncol Clin N Am 2003; 12: 231-242.

94. Coppa J, Pulvirenti A, Schiavo M, et al. Resection versus transplantation for liver metastases from neuroendocrine tumors. Transplant Proc 2001; 33: 1537-1539.

95. Nobel YR, Goldberg DS. Variable Use of Model for End-Stage Liver Disease Exception Points in Patients With Neuroendocrine Tumors Metastatic to the Liver and Its Impact on Patient Outcomes. Transplantation 2015; 99 (11): 2341-2346.

96. Fan ST, Le Treut YP, Mazzaferro V, Burroughs AK, Olausson M, Breitenstein S, Frilling A. Liver transplantation for neuroendocrine tumour liver metastases. HPB (Oxford) 2015; 17 (1): 23-28.

97. Mazzaferro V, Sposito C, Coppa J, Miceli R, Bhoori S, Bongini M, Camerini T, Milione M, Regalia E, Spreafico C, Gangeri L, Buzzoni R, de Braud FG, De Feo T and Mariani L. The Long-Term Benefit of Liver Transplantation for Hepatic Metastases from Neuroendocrine. American Journal of Transplantation 2016; 16: 2892-2902.
98. Kennedy A, Bester L, Salem R, Sharma RA, Parks RW, Ruszniewski P, NET-Liver-Metastases Consensus Conference. Role of hepatic intra-arterial therapies in metastatic neuroendocrine tumours (NETTNE): guidelines from the NET-Liver-Metastases Consensus Conference, HPB (Oxford) 2015; 17 (1): 29-37.

99. Gupta S, Johnson MM, Murthy R, Ahrar K, Wallace MJ, Madoff DC, McRae SE, Hicks ME, Rao S, Vauthey JN, Ajani JA, Yao JC. Hepatic arterial embolization and chemoembolization for the treatment of patients with metastatic neuroendocrine tumors: variables affecting response rates and survival. Cancer 2005; 104 (8): 1590-1602.

100. Gupta S. Intra-arterial liver-directed therapies for neuroendocrine hepatic metastases. doi:10.1055/s-0033-1333651, Semin Intervent Radiol 2013; 30 (1): 28-38.

101. Nigri G, Petrucciani N, Debs T, et al. Treatment options for PNET liver metastases: a systematic review. World J Surg Oncol 2018; 16 (1): 142. 10.1186/s12957-018-1446-y.

102. Boas FE, Kamaya A, Do B, et al. Classification of hypervascular liver lesions based on hepatic artery and portal vein blood supply coefficients calculated from triphasic CT scans. J Digit Imaging 2015; 28: 213-223.

103. Grozinsky-Glasberg S, Kaltsas G, Kaltsatou M, Lev-Cohain N, Klimov A, Vergadis V, Uri I, Bloom AI, Gross D. Hepatic intraarterial therapies in metastatic neuroendocrine tumors: lessons from clinical practice. Endocrine 2018; 60 (3): 499-509.

104. Madoff DC, Gupta S, Ahrar K, Murthy R, Yao JC. Update on the management of neuroendocrine hepatic metastases. J Vasc Interv Radiol 2006; 17 (8): 1235-1249.

105. Geschwind JF, Kaushik S, Ramsey DE, Choti MA, Fishman EK, Kobeiter H. Influence of a new prophylactic antibiotic therapy on the incidence of liver abscesses after chemoembolization treatment of liver tumors. J Vasc Interv Radiol 2002; 13 (11): 1163-1166.

106. Fiore F, Del Prete M, Franco R, Marotta V, Ramundo V, Marciello F, Di Sarno A, Carratù AC, de Luca di Roseto C, Colao A, Faggiano A. Transarterial embolization (TAE) is equally effective and slightly safer than transarterial chemoembolization (TACE). Endocrine 2014; 47 (1): 177-182.

107. Chen JX, Wileyto EP, Soulen MC. Randomized Embolization Trial for NeuroEndocrine Tumor Metastases to the Liver (RETNET): study protocol for a randomized controlled trial. doi:10.1186/s13063-018-2782-5, Trials 2018; 19 (1): 390.

108. Pitt SC, Knuth J, Keily JM, McDermott JC, Weber SM, Chen H, Rilling WS, Quebbeman EJ, Agarwal DM, Pitt HA. Hepatic neuroendocrine metastases: chemo- or bland embolization? J Gastrointest Surg 2008; 12 (11): 1951-1960.

109. Murthy R, Kamat P, Nunez R, Madoff DC, Gupta S, Salem R, Yao JC. Yttrium-90 microsphere radioembolotherapy of hepatic metastatic neuroendocrine carcinomasafter hepatic arterial embolization. J Vasc Interv Radiol 2008; 19 (1): 145-145.

110. Tong AK, Kao YH, Too CW, Chin KF, Ng DC, Chow PK. Yttrium-90 hepatic radioembolization: clinical review and current techniques in interventional radiology and personalized dosimetry. doi:10.1259/bjr.20150943, Br J Radiol 2016; 89 (1062): 20150943. 
111. Braat AJAT, Kappadath SC, Ahmadzadehfar H, Stothers CL, Frilling A, Deroose CM, Flamen P, Brown DB, Sze DY, Mahvash A, Lam MGEH. Radioembolization with (90)Y Resin Microspheres of Neuroendocrine Liver Metastases: International Multicenter Study on Efficacy and Toxicity. doi: 10.1007/ s00270-018-2148-0, s.l.: Cardiovasc Intervent Radiol 2019; 42 (3): 413-425.

112. NCCN clinical practice guidelines in oncology: neuroendocrine and adrenal tumors. Version. NCCN. [En línea] 1.2019. [Citado el: 20 de 01 de 2020.] https://www.nccn.org/professionals/ physician_gls/pdf/neuroendocrine.pdf.

113. Baldelli R, Barnabei A, Rizza L, et al. Somatostatin analogs therapy in gastroenteropancreatic neuroendocrine tumors: Current aspects and new perspectives. Front Endocrinol (Lausanne) 2014; 5: 7.

114. Zamora V, Cabanne A, Salanova R, Bestani C, Domenichini E, Marmissolle F, Giacomi N, O'Connor J, Méndez G, Roca E; Argentum Working Group Buenos Aires and La Plata, Argentina. Immunohistochemical expression of somatostatin receptors in digestive endocrine TUMOURS. Digestive and Liver Disease 2010; 42: 220-225.

115. Rubin J, Ajani J, Schirmer W, et al. Octreotide acetate longacting formulation versus open-labelsubcutaneous octreotide acetate in malignant carcinoid syndrome. J Clin Oncol 1999; 17: 600-606.

116. Khan MS, El-Khouly F, Davies P, Toumpanakis C, Caplin ME. Long-term results of treatment of malignant carcinoid syndrome with prolonged release Lanreotide (Somatuline Autogel). doi: 10.1111/j.1365-2036.2011.04693.x, Aliment Pharmacol Ther 2011; 34 (2): 235-242.

117. Vinik AI, Wolin EM, Liyanage N, Gómez-Panzani E, Fisher GA. Efficacy and safety as a carcinoid syndrome treatment (elect): a randomized, double-blind, placebo-controlled trial. Study Group Evaluation Of Lanreotide. Endocr Pract 2016; 22 (9): 1068-1080.

118. Kulke M, Horsch D, Caplin M, et al. Telotristat etiprate is effective in treating patients with carcinoid syndrome that is inadequately controlled by somatostatin analog therapy: The phase 3 TELESTAR clinical trial. ESMO 2015; Abstr LBA37.

119. Arnold R, Rinke A, Klose KJ, et al. Octreótido versus octreótido plus interferon-alpha in endocrine gastroenteropancreatic tumors: a randomized trial. Clin Gastroenterol Hepatol 2005; 3: 761-771

120. Faiss S, Pape UF, Bohmig M, et al. Prospective, randomized, multicenter trial on the antiproliferative effect of lanreotide, interferon Alfa, and their combination for therapy of metastatic neuroendocrine gastroenteropancreatic tumors-the International Lanreotide \& Interferon-Alfa StudyGroup. J Clin Oncol 2003; 21: 2689-2696.

121. Rinke A, Müller HH, Schade-Berittinger C, et al. Placebo-controlled, double-blind, prospective, randomized study on the effect of octreotide LAR in the control of tumor growth in patients with metastatic neuroendocrine midgut tumors: A report from the PROMID Study Group. J Clin Oncol 2009; 27: 4656-4663.

122. Caplin ME, Pavel M, C'wikła JB, et al. Lanreotide in metastatic enteropancreatic neuroendocrine tumors. N Engl J Med 2014; 371: 224-233.
123. Yao JC, Fazio N, Singh S, et al. Everolimus for the treatment of advanced, non-functional neuroendocrine tumours of the lung or gastrointestinal tract (RADIANT-4): a randomised, placebocontrolled, phase 3 study. Lancet 2016; 387: 968-977.

124. Strosberg J, El-Haddad G, Wolin E, et al. Phase 3 trial of $177 \mathrm{Lu}-$ dotatate for midgut neuroendocrine tumors. N Engl J Med 2017; 376: 125-135.

125. Brabander T, van Zwan WA, Teunissen JJM, et al. Long-term efficacy, survival, and safety of [177Lu-DOTA0,Tyr3] octreotate in patients with gastroenteropancreatic and bronchial neuroendocrine tumors. Clin Cancer Res 2017; 23: 4617-4624.

126. Dioca MH, Diaz C, et al. Efficacy and Safety of Peptide Receptor Radionuclide Therapy (PRRT) 90Y-Dotatoc in Neuroendocrine Tumors (NETs) Patients: Single-Institution Retrospective Analysis. ENETS 2019; Abstract K15.

127. Strosberg J, et al. The Role of chemotherapy in well-differentiated GEP neuroendocrine tumours. Front Horm Res 2015; 44: 239-247.

128. Ferrarotto R, et al. Combination of capecitabine and oxaliplatin is an effective treatment option for advanced neuroendocrine tumours. Rare Tumours 2013; 24: e35.

129. Dussol AS, et al. Gemcitabine and oxaliplatin or alkylating agents for neuroendocrine tumours: comparison of efficacy and search for predictive factors guiding treatment choice. Cancer 2015; 121: 3428-3434.

130. Yao JC, et al. Everolimus for advanced pancreatic neuroendocrine tumours. N Engl J Med 2011; 364: 514-523.

131. Raymond E, et al. Sunitinib malate for the treatment of pancreatic neuroendocrine tumours. N Engl J Med 2011; 364: 501-513.

132. Bodei L, et al. The joint IAEA, EANM, and SNMMI practical guidance on peptide receptor radionuclide therapy (PRRNT) in neuroendocrine tumours. Eur J Nucl Med Mol Imaging 2013; 40: 800-816.

133. Kwekkeboom DJ, et al. Treatment with the radiolabeled somatostatin analogue [177 Lu-DOTA 0,Tyr3] octreotate: toxicity, efficacy, and survival. J Clin Oncol 2008; 26: 2124-2130.

134. Munhoz RR, et al. Combination of irinotecan and a platinum agent for poorly differentiated neuroendocrine carcinomas. Rare Tumours 2013; 5: e39.

135. Bezerra EB, et al. Poorly differentiated neuroendocrine tumours. Neuroendocrine Tumour 2011: 157-176.

136. Sorbye $\mathrm{H}$, et al. GEP high-grade neuroendocrine carcinoma. Cancer 2014; 120: 2814-2823.

137. Tang LH, et al. A practical approach to the classification of WHO grade 3 (G3) well-differentiated neuroendocrine tumour (WD-NET) and poorly differentiated neuroendocrine carcinoma (PD-NEC) of the pancreas. Am J Surg Pathol 2016; 40: 1192-1202.

138. Walter DT, et al. Characteristics, prognosis and treatments of 294 patients with poorly differentiated neuroendocrine carcinoma: the FFCD-GTE national cohort. J Clin Oncol 2015; 33 (May 20 Supplement): 4095.

139. Welin S, et al. Clinical effect of temozolomide-based chemotherapy in poorly differentiated endocrine carcinoma after progression on first line chemotherapy. Cancer 2011; 117: 4617-4622. 


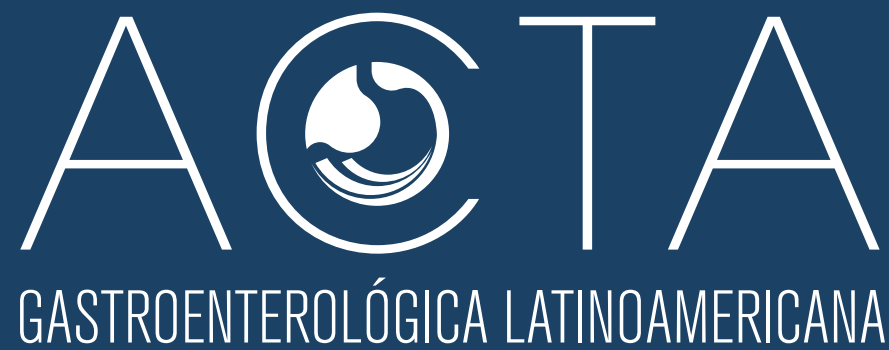

Vol 50 Supl. №1 año 2020 